U.S. Army Corrosion Prevention and Control Program

\title{
Innovative Corrosion-Resistant Coatings for Heat Distribution Piping at Fort Jackson
}

Charles P. Marsh, Alfred D. Beitelman, and Ryan J. Franks

June 2007

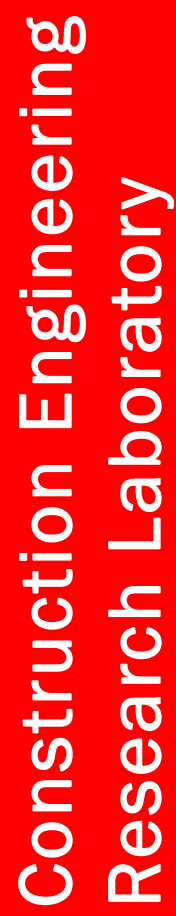

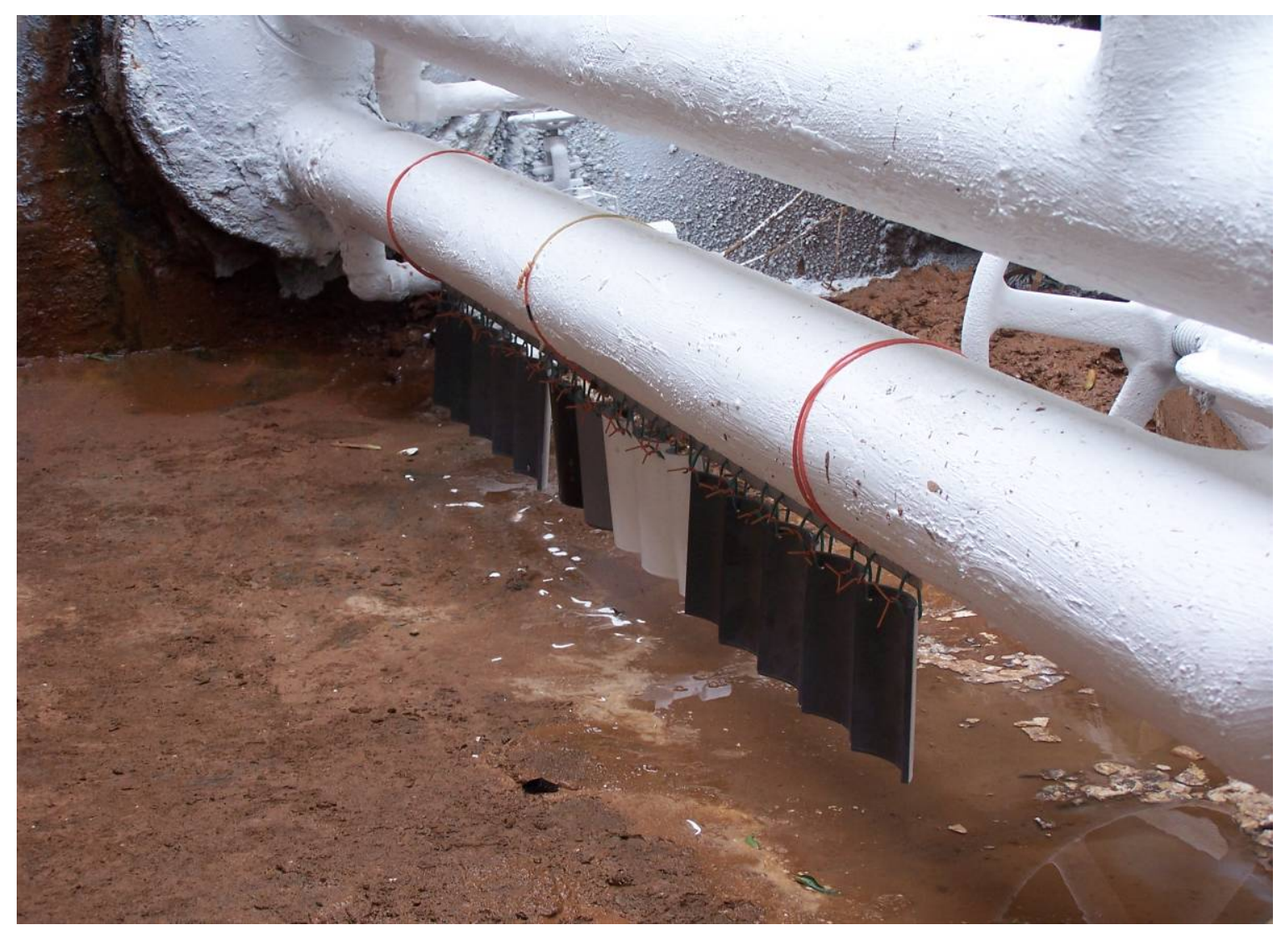




\title{
Innovative Corrosion-Resistant Coatings for Heat Distribution Piping at Fort Jackson
}

\author{
Charles P. Marsh, Alfred D. Beitelman, and Ryan J. Franks \\ Engineer Research and Development Center \\ Construction Engineering Research Laboratory \\ 2902 Newmark Drive \\ Champaign, IL 61822
}

Final report

Approved for public release; distribution is unlimited.

Prepared for U.S. Army Installation Management Command (IMCOM) Arlington, VA 22202

Under U.S. Army CPC Project IMA-2 


\begin{abstract}
Heat distribution systems are an integral part of military facility and installation infrastructure. These systems include numerous manholes that represent weak points in the overall efficiency, reliability, and service life of heating infrastructure. This report discusses the demonstration of an insulating ceramic paint and primer applied to coat manholes, piping, and appurtenances at Fort Jackson, SC, and the results obtained. The ceramic paint helps to prevent corrosion and heat loss while also significantly mitigating heat-related safety hazards to workers in the treated manhole. Because these issues are important operational concerns for every military facility, ceramic coatings represent a beneficial facility engineering technology that should be considered for wider adoption in heat distribution systems.
\end{abstract}

DISCLAIMER: The contents of this report are not to be used for advertising, publication, or promotional purposes. Citation of trade names does not constitute an official endorsement or approval of the use of such commercial products. All product names and trademarks cited are the property of their respective owners. The findings of this report are not to be construed as an official Department of the Army position unless so designated by other authorized documents. 


\section{Contents}

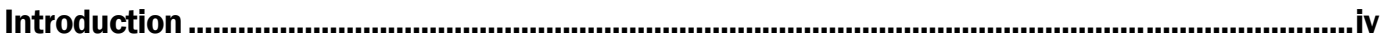

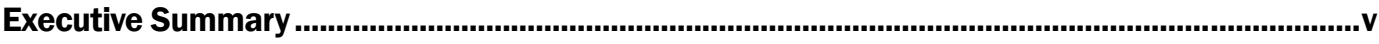

Unit Conversion Factors...........................................................................................................vi

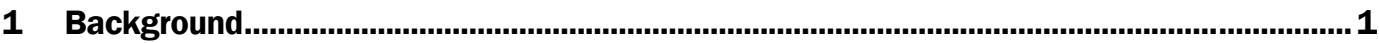

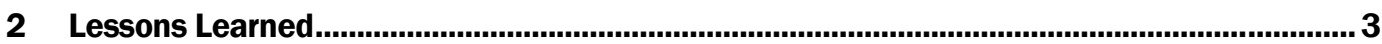

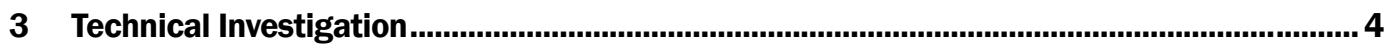

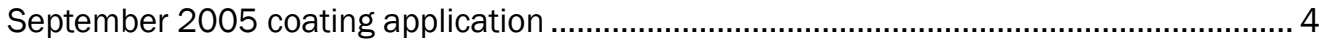

Site 1 - Corner of Marion and Hill Streets................................................................................ 4

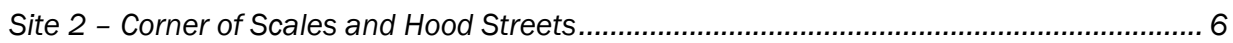

Site 3 - Sumter Street behind Building 2179................................................................. 7

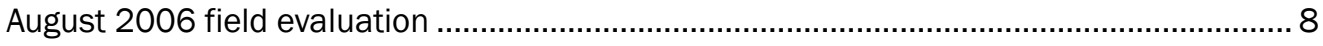

Site 1 - Corner of Marion and Hill Streets.............................................................................. 8

Site 2 - Corner of Scales and Hood Streets........................................................................ 9

Site 3 - Sumter Street behind Building 2179................................................................... 9

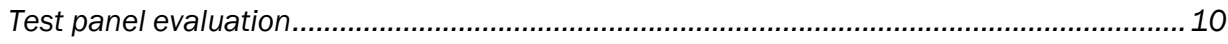

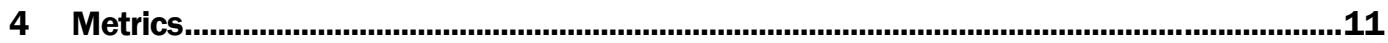

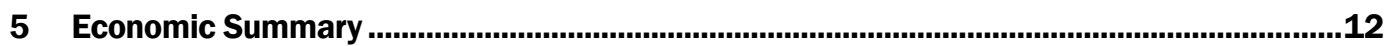

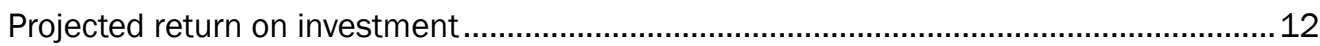

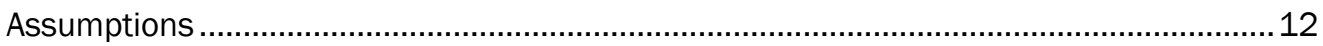

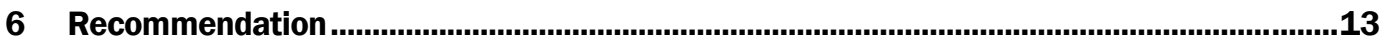

7 Implementation ..............................................................................................................14

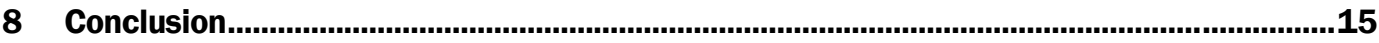

Appendix A: Project Management Plan (PMP) …...............................................................16

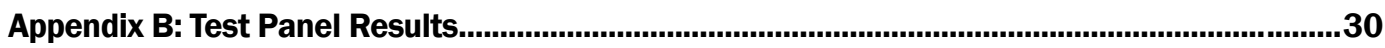

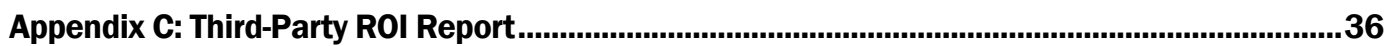

Report Documentation Page 


\section{Introduction}

This demonstration was performed for the U.S. Army Installation Management Command (IMCOM) under U.S. Army Corrosion Prevention and Control (CPC) Program Project IMA-2; Military Interdepartmental Purchase Requests MIPR5CCERB1011 and MIPR5CROBB1012, dated 15 December 2005. The proponent was the U.S. Army Office of the Assistant Chief of Staff for Installation Management (ACSIM). The technical monitors were Paul M. Volkman (IMPW-E) and David N. Purcell (DAIM-FDF). The stakeholders are Mr. Smith (Fort Jackson DPW), Mr. Volkman, Steve Jackson (IM-SERO), Mr. Purcell (DAIM-FDF), as well as Tri-Services WIPT representatives, Ms. Nancy Coleal (AFCESA/CESM) and Tom Tehada (NFESCX). The customer was Mr. Smith, Fort Jackson DPW.

The work was performed by the Materials and Structures Branch (CF-M) of the Facilities Division (CF), Construction Engineering Research Laboratory - Engineer Research and Development Center (ERDC-CERL). The Program Manager for the ERDC-CERL CPC Program was Dr. Ashok Kumar. The ERDC-CERL CPC Program Project Officer was Vincent F. Hock (CEERD-CF-M) and the Associate Project Officer was Dr. Charles P. Marsh (CEERD-CF-M). Dr. Marsh was assisted by Alfred D. Beitelman (CEERD-CF-M) of the Paint Technology Center at ERDC-CERL. The coatings work was done under contract with Twin Cities, Inc., Columbia, SC. At the time of coating application quality assurance was performed on site by Mr. Beitelman. Economic analysis was performed by The PERTAN Group, Champaign, IL. The project was facilitated by the assistance and cooperation of Steve Smith, Fort Jackson Directorate of Public Works, and George Dibb, Fort Jackson Department of Logistics and Engineering.

At the time this report was prepared, the Chief of the ERDC-CERL Materials and Structures Branch was Vicki L. Van Blaricum (CEERD-CF-M), the Chief of the Materials and Structures Branch was L. Michael Golish, (CEERD-CF), and the Technical Director for Installations was Martin J. Savoie (CEERD-CV-ZT). The Deputy Director of ERDC-CERL was Dr. Kirankumar Topudurti and the Director was Dr. Ilker Adiguzel.

The Commander and Executive Director of ERDC was COL Richard B. Jenkins and the Director was Dr. James R. Houston. 


\section{Executive Summary}

An innovative ceramics-based thermal barrier coating technology was implemented at Fort Jackson, SC. The coating was monitored for 1 year through periodic inspections, including assessment of coated sample specimens exposed to the interior manhole operating environment. The coating durability was found to be excellent, and the usually corrosive heat distribution system (HDS) manhole environment mitigated. The return on investment was found to be 58 .

The primary lessons learned were that it is necessary to arrange for coating application during prescheduled system shutdowns (which typically occur only during short periods in the spring and fall), and that the addition of extra approved conventional insulation can further improve the economic benefits of the coating. The economic analysis base comparison case assumed the pipes to be fully insulated, but it is typical for insulation to be missing from one or more portions of HDS manhole piping.

When this coating is used, it is recommended that the existing pipes be partially re-insulated so as to approximate the thermal properties of a newly constructed system. 


\section{Unit Conversion Factors}

\begin{tabular}{|l|c|l|}
\hline Multiply & By & To Obtain \\
\hline degrees Fahrenheit & $(\mathrm{F}-32) / 1.8$ & degrees Celsius \\
\hline feet & 0.3048 & meters \\
\hline gallons (U.S. liquid) & $3.785412 \mathrm{E}-03$ & cubic meters \\
\hline inches & 0.0254 & meters \\
\hline mils & 0.0254 & millimeters \\
\hline square feet & 0.09290304 & square meters \\
\hline
\end{tabular}




\section{Background}

Many U.S. Army installations are served by district heat distribution systems (HDSs) that provide space heating and hot water to the facilities. HDSs are large, complex networks of highly interdependent components, and the deterioration of one component affects the performance and deterioration rate of nearby or related components.

Manholes usually serve as valved take-offs to individual buildings, and they house many critical HDS components. Carrier pipes inside manholes are usually wrapped with insulation to prevent heat loss and to protect service personnel from burns upon entering the manhole. Nevertheless, during routine heat distribution service, the localized environment inside HDS manholes is typically hot and humid, which is severely corrosive to exposed steel. Furthermore, water tends to infiltrate the manhole from outside or though pinhole leaks in pipes. When water collects in the manhole or becomes trapped within in the pipe insulation, corrosivity intensifies and carrier pipes can deteriorate prematurely. As degradation of the insulation and steel accelerate, the useful service life of pipes may decrease from 25 years to as little as 10 or 15 years.

The corrosion of the carrier pipe in the manholes also creates problems that propagate though other components in the same manhole and the connecting pipes. ${ }^{1}$ Protecting the carrier pipe inside manholes against corrosion extends the service life of the entire HDS considerably, so it is desirable to have a cost-effective coating alternative to protect the carrier pipes against corrosion while additionally providing enough thermal insulation to help protect service personnel inside the manhole. Improvements in worker safety increase the likelihood that maintenance will be performed on a timely basis.

In addition, flooded manholes are at a near-optimal temperature for nucleate boiling, which can result in excessive heat loss. Using conservative unit energy costs, a boiling manhole is estimated to lose from $\$ 50,000$ to $\$ 125,000$ worth of heat per year if not repaired. ${ }^{2}$ Boiling manholes often

\footnotetext{
${ }^{1}$ Couch, Robert O. 1993. Underground heat distribution systems. 1993 Federal Section Conference: May 20 - 21, 1993. Arlington, VA: IDCA.

2 Marsh, Charles P., and Terrill R. Laughton. June 1998. Boiling Manhole Heat-Loss Calculations.
} 
go uncorrected for years, and their premature failure can only be reversed through expensive repair or replacement projects.

Because HDS manholes are both a critical necessity and a system vulnerability, better methods are needed to protect manhole pipes from corrosion. The Directorate of Public Works at Fort Jackson, SC, the U.S. Army Installation Management Command (IMCOM), and the Office of the Assistant Chief of Staff for Installation Management (ACSIM) have identified heat distribution systems as a critical part of the infrastructure needed to support the installation mission.

The project documented here uses a liquid ceramic coating and primer system to protect bare manhole piping in heat distribution systems. This class of coatings has been used for more than 10 years in industrial settings but is not currently used or HDS manhole piping on Army installations. Upon application of this coating the overall environment will be rendered significantly less corrosive while directly protecting the piping and associated segments. 


\section{Lessons Learned}

One of the primary lessons learned from this work is that the insulating value of the ceramic coating alone is significantly lower than intact conventional insulation. Therefore, it is recommended that a partial amount of approved conventional insulation be used in conjunction with the insulating coating. In a typical situation this will upgrade uninsulated piping both for corrosion protection and improved energy efficiency.

Another lesson learned is that scheduling the coating application can be a significant challenge. It is essential that this coating material be applied to a de-energized system and be given enough time to cure before the HDS system is fully re-energized. A typical HDS services a number of installation customers all year for both space heating and domestic hot water. Scheduled maintenance is usually performed over an interval of about 2 weeks in both the spring and the fall, so these would appear to be the best opportunities to apply the coating.

Also, as based on experience but also applicable to this work, expert inspection during the surface preparation and coating work is essential. Otherwise there is a risk that less than adequate attention will be applied and a poor coating job will result. 


\section{Technical Investigation}

\section{September 2005 coating application}

At Fort Jackson a number of manholes were prepared to be primed and subsequently topcoated with the insulating ceramic coating. A number of test panels were placed at each site for periodic sampling and field evaluation in order to monitor the condition of the coating over time. Also, a small ancillary investigation was performed in which a fiberglass mesh laminate material was embedded in the ceramic coating system along a small portion of the manhole piping. The purpose of the side investigation was to observe how the fiberglass reinforcement may affect the performance of the ceramic coating system. Details of the work are presented below.

\section{Site 1 - Corner of Marion and Hill Streets}

This pit is approximately $15 \mathrm{ft}$ square and $10 \mathrm{ft}$ deep. It contains dual hot water pipes with a surface temperature on the upper pipe of $182{ }^{\circ} \mathrm{F}$ and on the lower pipe of $152^{\circ} \mathrm{F}$. (Chilled water pipes in the pit were not a part of the contract.) Main pipes have an exterior diameter of approximately $61 / 2$ in. and a length of $13 \mathrm{ft}$. There are two large valves on the main pipes and eight smaller valves on side pipes of $1-2$ in. diameters. Total area to be painted was estimated to be approximately $90 \mathrm{sq} \mathrm{ft}$. The pipes enter the pit from the west and exit to the east in 24 in. conduits. They are fully exposed in the pit. Insulation was removed on Monday (29 August 2005) and surface preparation and priming was conducted on Tuesday. Surface preparation resulted in holes in the conduit on the east end of the pit. Holes in the top of the conduit were numerous. Water squirted from holes in the side on the conduit, causing some delay in surface preparation. A 1 in. pipe plug was removed in an effort to drain the conduit, but after 2 hours water was still squirting from the holes halfway up the side, so the plug was replaced and work continued. Abrasive blasting was conducted using silica sand having a designation of BX12. It had a wide gradation and produced a surface profile (replica tape) of 3.5-3.7 mils. Approximately half of a 5 gallon batch of MIL-DTL-24441 Formula 159 (manufactured by BLP Mobile) was mixed, and only a small portion of it was used. Application was with an electrically operated airless spray unit using a 517 tip. Mixing and application went smoothly. Thickness measurements the following day 
ranged from 3-15 mils with most of the readings in the 7-8 mil range. The coating was smooth and had no notable runs, sags, or instances of overspray.

On Thursday morning the initial topcoat was applied by airless spray using a 517 tip. The product, TC HB Ceramic manufactured by Capstone Manufacturing Co., Seattle, WA, was sprayed without thinning. The application had extensive overspray, especially on the west end of the top pipe. Water was added in an effort to smooth out the application. The resulting application had extreme thickness variations. Bubbling was noted on several areas on the upper pipe. (This is the hottest pipe and the thickest application.) Some bubbled areas were removed with a knife shortly after the application and the areas repaired. Other bubbled areas were removed with a knife on Friday. It was noted that adhesion to the primer on the top of the west end of the top pipe was poor. It is thought this was due to the overspray landing on the pipe prior to the paint application. Thickness measurements indicated the topcoat to be as little as 15 mils on undersides and hard to coat areas to near $1 / 8$ in. on the top of some pipe areas. Most application was in the 20 to 30 mil range.

On Friday afternoon the second topcoat was applied by airless spray using a 515 tip. The application had no notable overspray.

After a 3 day weekend the coating thickness was measured on Tuesday, 6 September 2005. A few areas of the topcoat, primarily on the undersides of the pipes, were less than the required 45 mils. In those cases, the thickness was brought up to specification with a brush. Overall, the thickness of the final system is mostly in the $50-70$ mil range, with some areas on the east end being in excess of the 100 mil capability of the gage.

Temperature measurements were made with both an infrared (IR) thermometer and a contact thermometer. The readings are shown in Table 1.

Table 1. Temperature measurements from site 1 manhole.

$\begin{array}{lll}\text { Area } & \text { IR } & \text { Contact } \\ \text { West end } & 81-82 & 59-61 \\ \text { On fiberglass } & 71-75 & 52-55 \\ \text { East end (top) } & 72-78 & 48-55 \\ \text { (bottom) } & 65-66 & 50-51\end{array}$




\section{Site 2 - Corner of Scales and Hood Streets}

This pit is approximately $15 \mathrm{ft}$ square and $9 \mathrm{ft}$ deep and contains dual hot water pipes. The surface temperature on the upper pipe is $155^{\circ} \mathrm{F}$ and on the lower pipe it is $138^{\circ} \mathrm{F}$. (Chilled water pipes in the pit were not a part of the demonstration.) Pipes entering the pit have a diameter of approximately $61 / 2 \mathrm{in}$. for $9 \mathrm{ft}$, at which point the diameter is reduced to $41 / 2 \mathrm{in}$. for approximately $5 \mathrm{ft}$. There are $6 \mathrm{in}$. and $4 \mathrm{in}$. branches off the main pipes. There are three large valves on the main pipes and five smaller valves on side pipes with $1 \mathrm{in}$. diameters. The total area to be painted was estimated to be approximately 80 square $\mathrm{ft}$. The pipes enter the pit from the west and exit to the east in 24 in. conduits. They are fully exposed in the pit. Insulation was removed on Monday and surface preparation and priming were conducted on Thursday. An initial probe of rust with a putty knife on the west conduit opened a 2 in. diameter hole. There was concern that abrasive blast of the pipe in the area might perforate the pipe, so minimal blasting was performed within 16 in. of the conduit. All other areas of the pipes were blasted to the SSPC-SP6 (commercial) grade. Blast was conducted with silica sand having a designation of BX12. It had a wide gradation and produced a surface profile (replica tape) of 3.5-3.7 mils. A single 3 gallon pail of Wasser MC Zinc, Standard grade batch number 50213 was mixed for application. Only a fraction of this material was used. Application was with an electrically operated airless spray unit using a 517 tip. Mixing and application went smoothly; however, upon drying for several minutes gas bubbles began forming where the application was excessively thick. Thickness measurements the following day ranged from $3.6-$ 15 mils, with most of the readings in the $3.6-8$ mil range. Blistering was limited to a few small areas where the thickness was in excess of 10 mils. The blisters were removed with a razor blade and the coating touched up with a brush.

On Friday afternoon the initial topcoat was applied by airless spray using a 515 tip. The product, TC HB Ceramic manufactured by Capstone Manufacturing Co., Seattle, WA, was thinned with water. The application had no notable overspray, but some sagging was seen on areas of excessive thickness.

After a 3 day weekend the coating thickness was measured on Tuesday, 6 September 2005. A few areas of the topcoat, primarily undersides of the pipes were less than the required 45 mils so the thickness was brought up to specification requirements with a brush. Bubbling was again removed 
and touched up with a brush. Overall, the thickness of the final system was mostly in the 50-70 mil range, with some areas on the east end exceeding the 100 mil capability of the gage. Much of the excessive thickness was due to the amount of overspray and attempts to smooth the coating.

Temperature measurements were made using both an IR thermometer and a contact thermometer. Readings are shown in Table 2.

Table 2. Temperature measurements from site 2.

$\begin{array}{lll}\text { Area } & \text { IR } & \text { Contact } \\ \text { West end } & 81-82 & 55 \\ \text { On fiberglass } & 71-76 & 52-55 \\ \text { East end (top) } & 69-72 & 48-55 \\ \text { (bottom) } & 64-68 & 44-47\end{array}$

\section{Site 3 - Sumter Street behind Building 2179}

This pit is approximately $6 \mathrm{ft}$ square and $8 \mathrm{ft}$ deep. It has two pipes entering from the north and exiting the west. Upon arrival of the contractor the pit had approximately $2 \mathrm{ft}$ of water. The lower pipe was completely submerged and the upper pipe was submerged except for a small amount of insulation. The sump pump was not operational and the electrical outlet near the pit was dead. A new sump pump was purchased and a generator was used to drain the pit. This pit contains dual hot water pipes at ambient temperature. The pipes enter the pit from the north through a 20 in. conduit. They are $31 / 2 \mathrm{in}$. outside diameter and are reduced to $2 \mathrm{in}$. before exiting the pit through a 16 in. diameter conduit to the west. The upper pipe is approximately $7 \mathrm{ft}$ long and the lower one is $10 \mathrm{ft}$. There are two large valves on the main pipes and six small valves on 1 in. side pipes. The total area being painted was estimated to be approximately $50 \mathrm{sq} \mathrm{ft}$. Insulation was removed on Monday and surface preparation and priming were conducted on Wednesday. Blast was conducted with silica sand having a designation of BX12. It had a wide gradation and produced a surface profile (replica tape) of 3.5-3.8 mils. Quality of blast met the SSPC SP6 (commercial) grade in all areas. Approximately half of a 5 gallon batch of High Temp 60oZN HA manufactured by Hi-Temp Coatings of Acton, MA, was mixed, and only a small portion of this quantity was used. Mixing was aggravated by the marginal quality of the zinc component. The zinc was packaged in a plastic bag inside a 1 gallon can. Although there was a sack of desiccant in the can, it appeared that moisture had caused the zinc to clump. Application was with an electrically operated airless spray unit us- 
ing a 517 tip. Thickness measurements revealed all areas to be in the $2.7-$ 12 mil range, with most measurements in the $5-6$ mil range.

The first topcoat was applied Thursday morning. The product, TC HB Ceramic manufactured by Capstone Manufacturing Co., Seattle, WA, was thinned with water. The application had no notable overspray, but some sagging was seen on areas of excessive thickness. After drying overnight, spots of rust were noted in the recesses of flanges. Thickness measurements of the first topcoat varied widely, from completely missed areas to sagged areas with more than 30 mils of coating, probably due in part to the complicated surfaces and confined work area.

The second topcoat was applied Friday morning.

After a 3 day weekend the coating thickness was measured on Tuesday, 6 September 2005. A few areas of the topcoat, primarily undersides of the pipes, were less than the required 45 mils, so the thickness was brought up to specification requirements with a brush. Overall, the thickness of the final system is mostly in the $60-70$ mil range.

\section{August 2006 field evaluation}

On 27 August 2006 a final observation of the coated HDS manhole pipes was performed. The final set of test panels was retrieved and the condition of the applied coatings on the pipes was observed.

\section{Site 1 - Corner of Marion and Hill Streets}

The conduit was running water into the pit from both ends. The sump pump was operating and the pipes were dry. There was no evidence that the pipes had been under water over the previous year. The coating was in like-new condition except for rust that had dripped from overhead structural members. The areas on each pipe where the fiberglass laminate had been applied were in like-new condition, but there were no obvious benefits from the installation of the laminate. The pipes were hot to the touch but an inspector could touch the upper part 30 seconds without discomfort. The lower pipe could be held without discomfort. The test panels were retrieved for examination. There were no apparent changes other than the dirt accumulated from exposure. 


\section{Site 2 - Corner of Scales and Hood Streets}

The conduit was dripping water into the pit from both ends. It had developed additional rust in the areas of the holes and green moss had again begun to grow. The area where the pipes were not blasted due to concern about perforation had been coated, but some of the remaining scale was loosening. Spots of pinpoint rust were forming in the area. The sump pump was operating and the pipes were dry, but a waterline indicated the test panels as well as the bottom half the lower pipe had been under water at one time. The coating was in like-new condition except for the rust that had dripped from overhead structural members. The few blisters that had formed at the time of application had not changed in appearance or size. The area on each pipe where the fiberglass laminate had been applied were in like-new condition, but there were no obvious benefits from the installation of the laminate. Coating thickness in this area was apparently greater, and both the upper and lower pipes could be held with no discomfort. The test panels were retrieved for examination. There were no apparent changes other than the dirt accumulated from exposure.

\section{Site 3 - Sumter Street behind Building 2179}

The conduit was in good condition but there was about 5 in. of water in the pit. This pit does not have electric service or a working sump pump. There was no evidence that the pipes had been under water over the past year. The coating was in like-new condition except for rust that had dripped from overhead structural members. There did appear to be a greater amount of rust in the flanges and on a few bolt thread areas. This amount of rust was minor but did appear to be greater that that seen in similar areas at the other Fort Jackson sites. The difference may be that the primer used at site 3 did not contain zinc or that it did not flow into the tight areas as well as the other two primers. The areas on each pipe where the fiberglass laminate had been applied were in like-new condition, but there were no obvious benefits of the installation of the laminate. The top pipe was so hot it could be touched only for a short time before causing a burn. The lower pipe could be held without any discomfort, however. The test panels were retrieved for examination. There were no apparent changes other than the dirt accumulated from the exposure. 


\section{Test panel evaluation}

Figure 1 shows all three sets of test panels, and two control sets, after 12 months of exposure. Details about each panel and more photos are presented in Appendix B. In brief, however, it was determined that little to no coating degradation had occurred during the period of exposure. Some staining of the coating was observed in the site 2 specimens, but the coating integrity was unaffected.

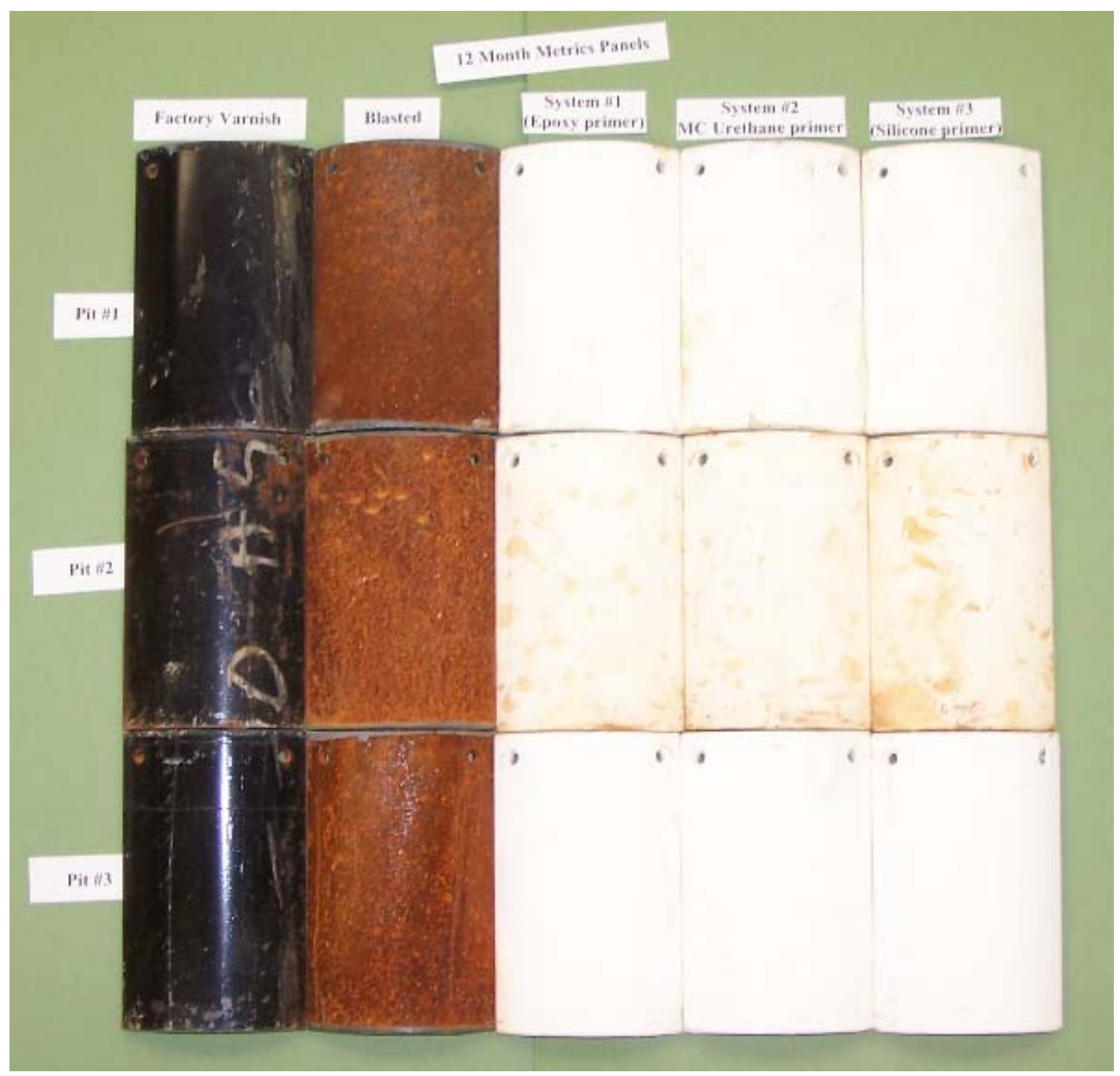

Figure 1. Samples showing test panel results after 12 months of exposure in three separate pits. The vertical columns, left to right, are factory varnish, blasted, system 1 (epoxy primer), system \#2 (MC urethane primer), and system 3 (silicone primer). 


\section{Metrics}

The following metrics were applied to assess the results of this demonstration.

Coating performance was assessed for chalking, flaking, and rusting with reference to ASTM standards D622, D610, D772. The manufacturer's recommendations for application were followed.

A number of factors were quantified to provide valid baseline cases either before or without the application of the coating system. Here, weight loss coupons (called test panels throughout this report) were used to determine the corrosion rate within the environment. In order to allow for periodic sampling, multiple coupons were be used. Three cases were covered:

1. uncoated pipe

2. any applicable existing coating (typically minimal to none)

3. the same coating system applied to the manhole piping as a control.

The temperature and relative humidity were monitored to quantify the modification of the environment and the resulting effect on corrosion.

Because the expected benefit of this technology will be realized over the long term, a full data set for quantifying the return on investment will not be available for years. However, relative frequency of leak repair, repair and maintenance costs, excessive heat loss, and overall system condition were monitored and compared with historical trends and experience, both at Fort Jackson and for similar heat distribution systems around the country. ${ }^{1,2}$

\footnotetext{
1 Marsh, Charles P., Nicholas M. Demetroulis, and James V. Carnahan. July 1996. Investigation of Preapproved Underground Heat Distribution Systems, USACERL Technical Report TR-96/77. Champaign, IL: U.S. Army Construction Engineering Research Laboratory.

2 Marsh, Charles P., Brian A. Temple, and Angela Kim. July 2001. Condition Prediction Model and Component Interaction Fault Tree for Heat Distribution Systems, ERDC/CERL TR-01-35. Champaign, IL: U.S. Army Engineer Research and Development Center - Construction Engineering Research Laboratory.
} 


\section{Economic Summary}

\section{Projected return on investment}

The projected return on investment (ROI) for this project was determined to be 58 . It should be noted that, strictly speaking, a return on investment is applicable specifically to cases in which an investment produces a profit or financial return. Because the economic benefit of this technology is cost savings rather than a hard financial return, it is technically more correct to express the benefit as a savings-to-investment ratio (SIR). The value of the benefit is the same, so the terms are interchangeable, but ROI is used here for discussion in the context of the Army CPC Program.

\section{Assumptions}

The full economic analysis is presented in Appendix C. The findings of the analysis were that the ceramic coating system provides a net savings of $\$ 63,366$ per manhole over a 20-year life cycle, and an ROI of 58 . The analysis also determined the payback period for the initial investment to be 16.2 years.

Not included in this analysis are the energy savings of providing a partial insulating capability where, typically, bare pipes are found after 7-10 years of service. Occasional manhole flooding and general wear and tear tends to degrade the insulation. The ceramics-based insulating coating provides some insulation value even when wet. Also not covered in the economic analysis is the improved worker safety factor, where the possibility of burns is virtually eliminated by application of a coating that is only warm to the touch while the HDS is operating. An additional value of the worker safety benefit is that maintenance is more likely to be performed on schedule where the danger of burns is reduced, thus promoting the long-term reliability and efficiency of the system in the support of mission objectives. 


\section{Recommendation}

It is recommended that the managers of U.S. military installations fully consider utilizing the subject insulating ceramic coating system on various HDS elements in manholes to prevent corrosion, extend infrastructure service life, and avoid potentially costly leaks and component replacement.

It also is recommended that a partial amount of conventional insulation material be used in conjunction with the ceramic coating system. Doing so while also applying the insulating ceramic coating will modify the internal manhole environment toward conditions that will greatly reduce corrosive degradation while restoring the full thermal insulation capacity to an asbuilt or "like-new" condition. 


\section{Implementation}

It is recommended that this technology be adopted widely and implemented by inclusion in the applicable Unified Facilities Guide Specifications (UFGS) and Technical Manuals (TM). In particular, UFGS-33 60 01, Valves, Piping, and Equipment in Valve Manholes (July 2006) would be the primary document in which to codify this change. In addition, UFGS3361 13, Pre-Engineered Underground Heat Distribution System (April 2006) may require modification if the conduit end plates are to be coated. Inclusion in the original design of new systems would also be aided by incorporating this technology in Army TM 5-810-17, Heating and Cooling Distribution. 


\section{Conclusion}

This project demonstrated the benefits of an innovative ceramics-based insulating coating system in protecting high-temperature HDS pipes located in manholes. Periodic field inspections and examination of exposed test panels were performed at intervals of 4,8 , and 12 months. In addition temperature measurements were used to estimate heat loss.

A third-party economic analysis estimated that the ROI for this technology would be about 58 , with an initial payback period of 16.2 years. These results however are somewhat skewed in that the base comparison case addressed insulated pipes whereas the piping insulation in manholes is often found to be significantly damaged or missing. The addition of some portion of the original intended insulation thickness could help to make up for the design insulating capacity not provided by the coating.

In addition to the extra corrosion protection provided by this coating system, in part through mitigation of the corrosive conditions in the manhole environment, the improvement in thermal performance should yield good returns on an ongoing basis, especially with expected long-term increases in energy costs. Also, system reliability enhancements provided by this technology offer a benefit in terms of improved mission support and readiness. 


\title{
Appendix A: Project Management Plan (PMP)
}

\author{
TRI-SERVICE PROGRAM \\ ARMY FACILITIES \\ CORROSION PREVENTION AND CONTROL PROJECT PLAN \\ Innovative Corrosion Resistant Materials/Indicator Coatings for High \\ Temp/Steam Piping at Ft. Jackson \\ Project No.: IMA2 \\ November 2004 \\ (as modified from 13 July 2004 version) \\ Submitted By: \\ Charles Marsh \\ U. S. Army Engineer Research \& Development Center (ERDC) \\ Construction Enqineering Research Laboratory (CERL)
}

Comm: $217-373-6764$

(Project Number to be assigned by OSD when approved) 


\section{STATEMENT OF NEED}

\section{PROBLEM STATEMENT:}

Ft. Jackson, IMA and ACSIM have identified heat distribution systems as a critical part of the infrastructure needed to support the installation mission. Duing their normal service life piping in heat distribution system (HDS) manholes throughout the Army and the Tri-Services routinely experience an enviromment that is both hot and humid. This results in an ongoing and severely conrosive environment to which bare and often uninsulated steel piping is exposed. ${ }^{\prime}$ Add to this multiple occurrences of leaking valves, pinhole leaks in condensate lines, ground water ingress, and occasional flooding and this accelerated degradation often results in the piping quickly reaching half of the useful life cycle (typically 25 years ${ }^{2}$ ) within five to eight years. In addition, flooded manholes are at a near optimal temperature for mucleate boiling and can result in excessive and additional heat loss. For example a boiling manhole is estimated to lose from $\$ 50,000$ to $\$ 125,000$ worth of heat per year if not repaired' while also prematurely degrading via conrosion the critical intemal piping counections and appurtenances. Boiling manholes can easily go uncorrected for six or more years, and their eventual replacement repair, due to their shortened useful life, will also be expensive. Given that the manholes are both necessary and required, but also represent a reliability weakness, a means to better protect the manhole piping is needed. Even in normal operation the warm-to-hot and often humid manhole environment is inherently prone to accelerated corrosive degradation.

\section{IMPACT STATEMENT:}

Implementation of this project will result in avoided adverse impact to mission critical basic and/or proficiency training through loss of building space heating and hot water supply. Similar impacts to other base operations will also be avoided. Other benefits will include significant reduction in operational and replacement expenses ${ }^{4}$ allowing more budgetary lee way for mission support, as well as improved system reliability and extended useful service life. Another plus is that maintenance worker safety will also be improved through less chance of bums, water hammer, catastrophic valve failure, and lack-of-oxygen confined space fatalities. More specifically, the expected benefits of innovative corrosion resistant coatings are to protect internal manhole piping connections (i.e., hot water/steam supply and retum line take offs from the main feeder trunk line) and valves from conrosion in a typically highly conrosive environment. An additional advantage of the intended innovative coating is to lower the hot pipe surface temperature

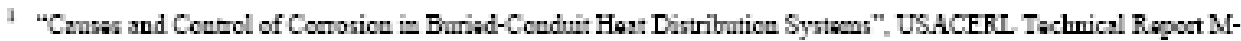
91/08 (July 1991), James R. Myars, Ellen G. Segan, Charles P. Mazuh, Vinceet F. Hock.

2 In addition, for long lived systems mandated by 10 CFR. 436.14(d)(2) not to exceed 25 yenrs

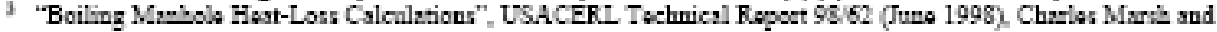
Terrill Laughtoe. Note: these calculations we an old Army "Red Book" [FY94, Vol I] cont of anergy value of $\$ 6.79$ par MBen.

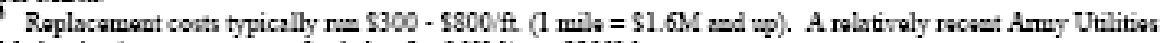
Modamization progrem was fundad at $5 \mathrm{x} \$ 60 \mathrm{M} / \mathrm{z}=\$ 300 \mathrm{M}$
} 
and provide bum protection to the maintenance worker. This also means that a modest amount of effective insulation is added in a small added thickness. Since heat distribution systems are in fact collections of interacting components ${ }^{5}$ the overall system condition will also be maintained. Taken all together these advantages result in a longer, energy efficient service life, lower life cycle cost operating costs, increases the likelihood of maintenance procedures being performed and an extended time between overall system replacement.

\section{PROPOSED SOLUTION}

\section{TECHNICAL DESCRIPTION:}

This project will use a liquid ceramic coating to coat newly constructed, bare, manhole piping in heat distribution systems (e.g., Utility Modemization jobs). This class of coatings has over 10 years of experience in industrial settings but is not currently used within the Anmy for HDS manhole piping. With as little as 180 mils a $350 \mathrm{~F}$ pipe can be rendered non-painful for contact with bare skin. However, mainly the overall environment will be rendered significantly less conrosive while directly protecting the piping. In addition, depending on the specific application situation, an indicator coating may also be applied. This will consist of either a distinctively colored intermediate layer to easily show by visual inspection that it's time for recoating, or, a thermal indicator coating which shows a color change above specific graded temperature. Either of these indicator coatings will yield an easily perceived "test result" showing the current status of the manhole piping and prompt appropriate maintenance procedures as needed.

\section{$\underline{\text { Technology Maturity: }}$}

This technology is mature and so low risk, with many years of proven experience. As one recent example a steam generation and distribution company in Detroit, MI is currently in the process of coating piping (including all apputenances such as valves, fittings, and connectors) in their 900 manholes with 60 mils of this type of costing. One beneficial effect has been to decrease the ambient working condition temperatures which allow crews to work longer and without excessive ventilation.

\footnotetext{
3 "Condition Prodiction Modal and Componsut Intoraction Fault Tres for Hezt Distribution Systems", Marsh, Templa, Kim, ERDCCERL TR-01-35 (July 2001).
} 


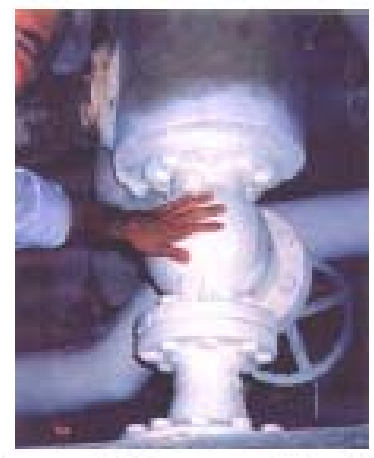

Figure 1: Commercial valve and piping coated with a liquid ceramic coating.

\section{RISK ANALYSIS:}

This is a low risk project in that the coating products are commercially available from multiple manufacturers. Ongoing, widespread industry experience over at least the last 10 years strongly indicates that successful application and long term performance should be expected. In addition, based on past working relationships at the first implementation site, Ft. Jackson, SC, they are very receptive to heat distribution system improvements. In fact, Ft. Jackson is one of the sites of a multi-year FEAP/FTAT project comparing concrete shallow trench to direct buried heat distribution systems in the $1990 \mathrm{~s}$. This prior work resulted in significant improvements in the applicable guide specifications, TM 5810-17 and AR 420-49. This project will be implemented at Ft. Jackson without the need of a phased approach.

\section{EXPECTED DELIVERABLES AND RESULTS/OUTCOMES:}

Depending upon manhole size and the associated intemal piping suface area, from 25 to 40 manholes will be upgraded with the application of liquid ceramic coatings. As needed an appropriate indicator coating will also be included. In addition, supplied to the installation will be draft contract language and specifications (e.g., suface preparation, product acceptance requirements, safety procedures, etc.) for use on additional applications. The expected outcome is that there will be less operational distribution heat loss, significantly less corrosion will occur on upgraded manhole piping and a more reliable and longer service heat distribution system should result. Follow up coating assessments will be used to futher assure and document expected performance.

PROGRAM MANAGEMENT: The Project Manager will be: Dr. Charles Marsh (ERDC-CERL Senior Researcher and Materials Engineer). The Associate Project Manager will be: Mr. David Kessler. The stakeholders will be Mr. Steve Jackson (IMASERO), and Mr. Tom Tehada (USN) and Ms. Nancy Coleal (USAF). Customers are: Mr. George Dibb, Department of Logistics and Engineening, Ft. Jackson. The approach will include contacting mechanisms such as Indefinite Delivery Indefinite Quantity (IDIQ) Contract. An IDIQ Task Order and/or a technically qualified 8A contract for this project are expected to be awarded by 1 month after receipt of finds. Direct Cite finds will be used for contracts for implementing innovative manhole piping coatings at Fort Jackson. 


\section{COST/BENEFITS ANALYSIS}

a. Funding (\$K):

$\begin{array}{lcc}\text { Funding Source } & \text { OSD } & \text { IMA } \\ \text { Labor } & \text { N/A } & 170 \\ \text { Materials } & \text { N/A } & 90 \\ \text { Travel } & \text { N/A } & 18 \\ \text { Report } & \text { N/A } & 15 \\ \text { Air Force/Navy Participation } & \text { N/A } & - \\ \text { SUBTOTAL } & \text { N/A } & 293 \\ \text { Overhead } & \text { N/A } & 67 \\ \text { TOTAL (SK) } & \text { N/A } & 360\end{array}$

\section{Development Project Budget}

The $\$ 360 \mathrm{~K}$ budget is realistic and adequate for the scope of the project. ERDCCERL has an historic and ongoing familiarity with the Ft. Jackson heat distribution system. This association dates back to at least the 1980 s heat distribution system upgrade and later associated FTAT (later FEAP) program and carriers through to a recent assessment performed for the Utilities Modernization program

\section{b. Return-On-Investment Computation}

Using the required OMB spreadsheet, and in accordance with OMB Circular A-94, a return-on-investment (ROI) of 15.74 was calculated (see Appendix 1 below along with installation specific supporting notes and cited references). The associated savings were $\$ 5.7 \mathrm{M}$. This ROI value is based on current best practices, as well as projected maintenance and rehabilitation practices and costs. In addition, conservative values for average energy costs and mostly labor based expenses for leak repair have been chosen since they are well documented.

\section{c. Mission Criticality}

The operational benefits of implementation of this technology for these mission critical systems are enhanced thermal efficiency, improved life cycle costs, lower ongoing operating costs, improved worker safety and increased system wide reliability for heat distribution systems. 


\section{SCHEDULE}

\section{MILESTONE CHART}

\section{Award Contract}

\section{EVENT}

Site Visit to Select Manholes

Select Liquid Ceramic and Indicator Coating

Products

Begin On Site Coating Application

Complete Coating Application

Complete Draft Contract Language and

Procurement Documents for Installation

Perform Follow Up Assessment

Complete Documentation (includes Final

Report, Procurement Specification, Ad Fliers)

Complete ROI Validation

\section{TIME}

(months after

receipt of funds)

1

2

2

3

5

6

10

12

a. Note: If project is approved, bi-monthly status reports will be submitted (i.e. starting the first week of the second month after contract award and every two months thereafter until final report is completed). This report will be submitted to the DoD CPC Policy \& Oversight office. Report will include project number, progress summary (and/or any issues), performance goals and metrics and upcoming events.

b. Examples of performance goals and metrics: include achieving specific milestones, showing positive trend toward achieving the forecasted ROI, reaching specific performance quality levels, meeting test and evaluation parameters, and/or successfully demonstrating a new system prototype.

\section{IMPLEMENTATION}

a. Transition approach: Unified Facilities Guide Specifications (UFGS), Engineering Instructions (EI), Technical Instructions (TI), and Technical Manuals (TM), including updates, along with a final report describing the details of the project, will be developed and posted to the OSD Conosion Exchange website under "Spec \& Standards" and "Facilities SIG." In addition, the guidance will be ERDC-CERL Corrosion Prevention and Control Program (CPCP) website. Coordination with potential users will be an essential part of the transition of the technology. It is the intent of the Project Management Plan (PMP) to implement this corrosion prevention and control technology at multiple regions and installations over the next six years, according to the schedule shown below. The UFGS, EIs, TIs, and TMs, including updates to existing guidance documents, 
developed for Anny-wide implementation during the FY05 project, will be utilized to facilitate the planned implementation over the next six years.

\begin{tabular}{|c|c|c|c|c|}
\hline FY & OSD Funds & HQ-MMA Matching & Planned Regions & Planned Installations \\
\hline 06 & $\$ 480 \mathrm{~K}$ & $\$ 480 \mathrm{~K}$ & SERO & Ft. Brage, Redistove Arsengl \\
\hline 07 & $\$ 4 \$ 0 \mathrm{~K}$ & $\$ 480 \mathrm{~K}$ & NERO & West Point, Ft. Lee \\
\hline 08 & S480K & $\$ 480 \mathrm{~K}$ & NERO NWRO & Ft. Riley, Ft McCoy \\
\hline 09 & $\$ 480 \mathrm{~K}$ & $\$ 480 \mathrm{~K}$ & NWRO & Ft. Lewis, Ft. Leovard Wood \\
\hline 10 & $\$ 480 \mathrm{~K}$ & $\$ 480 \mathrm{~K}$ & PARO & Ft. Richardson, Ft. Shafter \\
\hline 11 & $\$ 480 \mathrm{~K}$ & $\$ 490 \mathrm{~K}$ & NERO & APG, Ft. Belvoir \\
\hline
\end{tabular}

b. Potential ROI validation. ROI will be validated by comparison of coated manhole piping with otherwise identical but un-coated manhole piping. The calculated ROI for this project, which is based on current best practices, projected maintenance and rehabilitation cost, has the potential to increase over the multiple year implementation due to the reduction in down time, which will result in increased indirect savings. In subsequent years, the extension of useful and energy efficient service life of the heat distribution system, along with any applicable indirect savings, will be used to futher refine and validate the ROI calculation. Third party validation will be used to document the ROI savings performance of this project. This validation work will be performed by an impartial and technically qualified individual such as a NACE-certified Conrosion Expert or by an expert in heat transfer such as Mr. Bob O'Brien of Washington State University.

c. Final Report: A fimal report will be witten 60 days after the project is completed. The report will reflect the project plan format as implemented and will include lessons leamed.

\section{Projected Benefits}

Based on extensive industry experience over many years this coating system should reduce corrosion in what typically can be an adverse and high conosion environment (i.e., high temperature and high humidity). Additional benefits of increased energy efficiency and enhanced worker safety are also expected. Overall this project will help to prevent heat distribution system wide premature failure and excessive heat loss over and above the designed value. A more reliable supply of space heating and hot water, which often is also used in industrial process applications, will result in a positive impact to mission requirements and continued operational readiness at Ft. Jackson.

\section{Management Support}

This project is supported by the Ft. Jackson DPW Office as well as the IMA-SERO Region (see coordination sheet signatures). In addition, the Army (HQ-IMA and HQACSDM) have reviewed this project and provided matching funds for FY05. See associated Memorandum from ACSDM Director for Facilites and Housing. 
6. COORDINATION SHEET

ORGANIZATION SIGNATURE

\begin{tabular}{|l|l|}
\hline Project Manager & (see attached) \\
\hline ERDC/CERL Branch Chief & (see attached) \\
\hline Installation DPW POC & (see attached) \\
\hline IMA Region & (see attached) \\
\hline HQ IMA & (see attached) \\
\hline HQ ACSIM & (see attached) \\
\hline HQ AMC & $\begin{array}{l}\text { Hilton Mills approved signature is being sent } \\
\text { under separate cover. }\end{array}$ \\
\hline Tri-Service Facilities WIPT Chair & (see attached) \\
\hline
\end{tabular}

6. COORDINATION SHEET

ORGANIZATION

WIPT Chair

ACSIM

HQ IMA

IMA Region

Installation DPW

Installation $\mathrm{POC}$

ERDC/CERL Branch Chief

Project Manager

Service CPC IPT Representative
SIGNATURE.

DATE
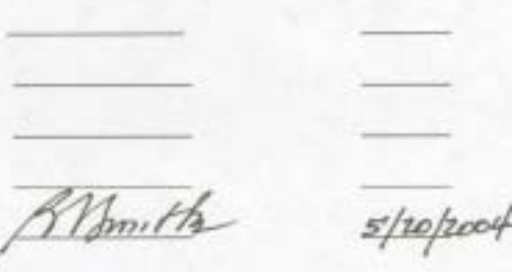

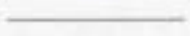

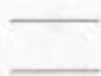


6. COORDINATION SHEET

ORGANIZATION

Project Manager

ERDC/CERL Branch Chief

Installation DPW POC

Installation Environmental POC

IMA Region (SE)

HQ IMA

HQ ACSIM

HQ AMC

Tri Service Facilities WIPT Chair

\section{SIGNATURE \\ DATE}

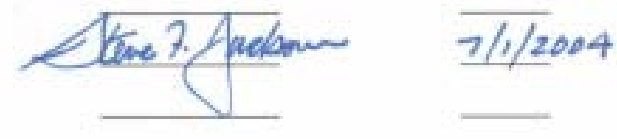

This is a TriService Project. Funds have been requested for Air Furce and Navy representatives to participate in the evaluation of technology implementation.

\section{COORDINATION SHEET}

\section{ORGANIZATION}

SIGNATURE

Project Manager

ERDCICERL, Branch Chief

Installation DPW POC

Installation Environmental POC

IMA Region

HQ IMA

HQ ACSIM

HQ AMC

Tri Service Facilities WIPT Chair
DATE
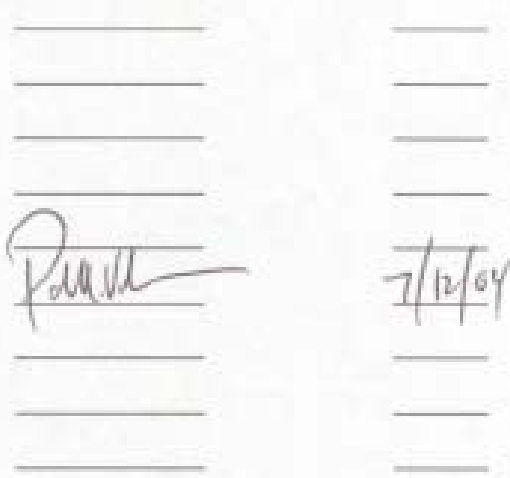

This is a TriService Project. Funds bave been requested for Air Force and Navy representatives to participste in the evaluation of iechaology implementition. 
6. COORDINATION SHEET

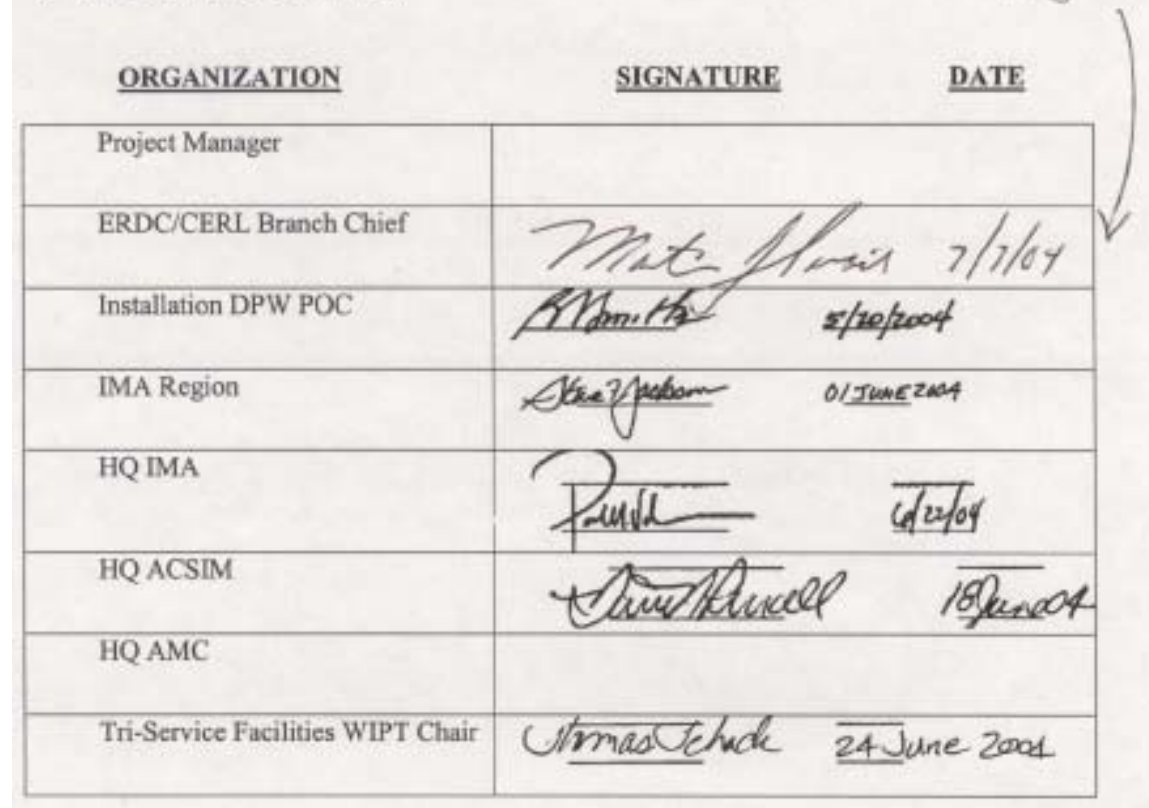

6. COORDINATION SHEET

\begin{tabular}{|c|c|c|}
\hline ORGANIZATION & SIGNATURE & DATE \\
\hline \multicolumn{3}{|l|}{ Project Manager } \\
\hline ERDCiCERL Branch Chief & & \\
\hline Installation DPW POC & \multicolumn{2}{|c|}{ s/20/2004t } \\
\hline IMA Region & Ekrezpotom & OlJunezant \\
\hline HQ IMA & & Gores \\
\hline HQ ACSIM & \multicolumn{2}{|c|}{ Hauntuarall } \\
\hline \multicolumn{3}{|l|}{ HQ AMC } \\
\hline Tri-Service Facilities WIPT Chair & Umasterude & ine 2004 \\
\hline
\end{tabular}


6. COORDINATION SHEET

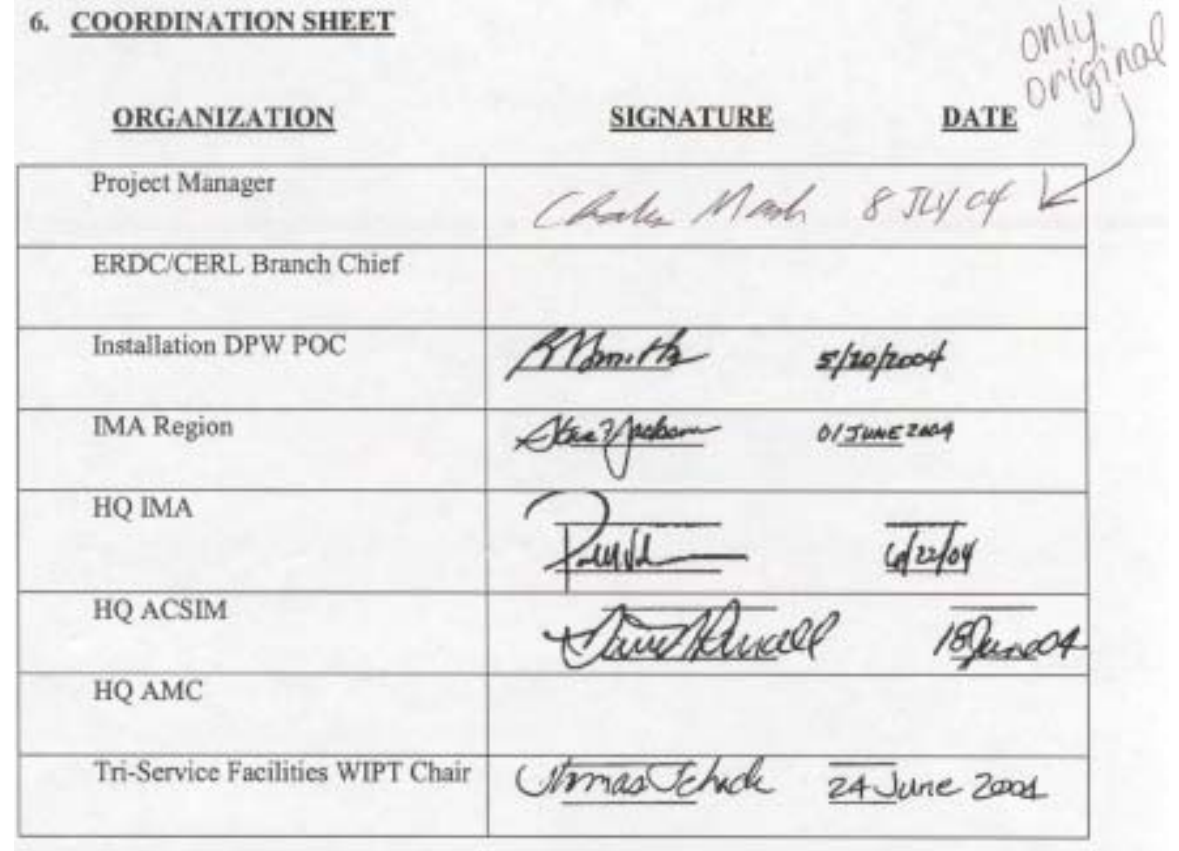

\section{COORDINATION SHEET}

\section{ORGANIZATION}

Project Manager

ERDC/CERL Branch Chief

Installation DPW POC

Installation Environmental POC

IMA Region

HQ IMA

HQ ACSIM

HQ AMC

Tri Service Facilities WIPT Chair
SIGNATURE $\quad$ DATE

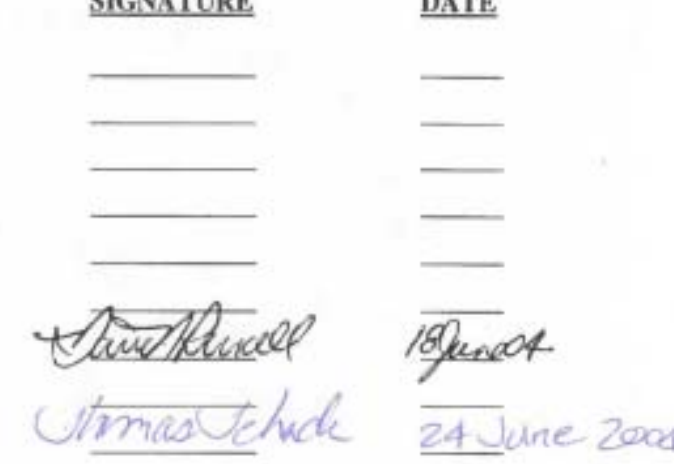

This is a Triservice Project. Funds have been requested far Air Force and Navy representatives to participate in the evaluation of technology implementation. 


\section{7. $\mathrm{APPENDICES}$}

Appendix 1: Potential ROI Calculations based on OMB Circular A-94

\section{Return on Investment Calculation}

\begin{tabular}{|c|c|c|c|c|c|c|c|}
\hline & & & Inves: & Iment Required & & & 360,000 \\
\hline & & & Return on In & vestment Ratio & 15.74 & Percent[ & $1574 \%$ \\
\hline & Net & Present Value & Costs and $\mathrm{B}$ & 9nefits/Savings & 14,047 & $5,680,170[$ & $5,665,123$ \\
\hline $\begin{array}{c}\text { A } \\
\text { Future } \\
\text { Year }\end{array}$ & $\begin{array}{c}\text { B } \\
\text { Baseline Costs }\end{array}$ & $\begin{array}{c}c \\
\text { Baseline } \\
\text { Besefits/Savings }\end{array}$ & $\begin{array}{l}\text { D } \\
\text { New System } \\
\text { Cests }\end{array}$ & $\begin{array}{c}\text { E } \\
\text { New System } \\
\text { Benefits/Savings }\end{array}$ & 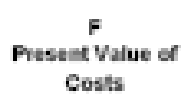 & 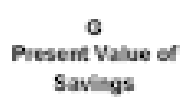 & $\begin{array}{c}\text { H } \\
\text { Tetal Present } \\
\text { Value }\end{array}$ \\
\hline & 30 & & 2000 & 62,429 & 1,829 & 58800 & 56938 \\
\hline & 50 & & 2000 & 62,420 & 1,747 & $5<954$ & 63200 \\
\hline & 300 & & 2000 & $117 \mathrm{gad}$ & 1,633 & 98,000 & 94977 \\
\hline & 50 & & 2000 & 117.890 & 1,526 & 90260 & 88769 \\
\hline & 50 & & 2000 & 122070 & 1,426 & 87,392 & 85960 \\
\hline & 500 & & 2008 & 1263,300 & 1,333 & 84457 & 83.54 \\
\hline & 50 & & 2008 & $173,2 \mathrm{ag}$ & 1,245 & 1003219 & 106967 \\
\hline & 50 & & 2000 & $160,0 \in d$ & 1,164 & $98 \in B$ & 97520 \\
\hline & 500 & & 2000 & 232948 & 1,088 & 128969 & 12588 \\
\hline 10 & 9300,000 & & 2000 & 2583,370 & 1,017 & 4873769 & 4,87279 \\
\hline 11 & & & & & & & \\
\hline 12 & & & & & & & \\
\hline 13 & & & & & & & \\
\hline 14 & & & & & & & \\
\hline 15 & & & & & & & \\
\hline & & & & & & & \\
\hline 17 & & & & & & & \\
\hline 18 & & & & & & & \\
\hline $\begin{array}{l}19 \\
20\end{array}$ & & & & & & & \\
\hline 21 & & & & & & & \\
\hline 28 & & & & & & & \\
\hline 23 & & & & & & & \\
\hline 24 & & & & & & & \\
\hline 25 & & & & & & & \\
\hline 26 & & & & & & & \\
\hline 27 & & & & & & & \\
\hline 28 & & & & & & & \\
\hline 28 & & & & & & & \\
\hline 34 & & & & & & & \\
\hline
\end{tabular}


Supporting calculations for Avoided Costs (Column E):

COL. E: AVOIDED COSTS

NOTE: HDS SYSTEM REPLACEMENT (yr 11 and after)

System length $(\mathrm{ft}): \quad 31000$

\begin{tabular}{|c|c|c|c|c|c|c|c|c|c|c|c|c|}
\hline YEAF & $\begin{array}{l}\text { gy } \\
\text { btu) }\end{array}$ & $\begin{array}{l}\text { \# man } \\
\text { holes } \\
\text { boiling }\end{array}$ & $\begin{array}{l}\text { excess MH } \\
\text { heat loss } \\
\text { (Mbtu/yr) }\end{array}$ & $\begin{array}{l}\text { excess } \mathrm{MH} \\
\text { energy loss } \\
\text { per year } \\
\text { (K\$/MH) }\end{array}$ & $\begin{array}{l}\text { No of } \\
\text { leaks }\end{array}$ & $\begin{array}{l}\text { Leak } \\
\text { repair } \\
\text { costs }\end{array}$ & $\begin{array}{l}\text { Total leak } \\
\text { repair costs } \\
\text { (K\$) }\end{array}$ & $\begin{array}{l}\text { Manhours } \\
\text { for yearly } \\
\text { manhole } \\
\text { inspection }\end{array}$ & $\begin{array}{l}\text { No. } \\
\text { man } \\
\text { holes }\end{array}$ & $\begin{array}{l}\text { \$ per } \\
\text { man } \\
\text { hour }\end{array}$ & $\begin{array}{l}\text { annual } \\
\text { inspection } \\
\text { costs (K\$) }\end{array}$ & $\begin{array}{l}\text { TOTAL } \\
\text { COL.E }\end{array}$ \\
\hline 1 & 6.79 & 1 & 7542.00 & 51.21 & 2 & 4.22 & 8.45 & 2 & 44 & 20 & 1.76 & 61.42 \\
\hline 2 & 6.79 & 1 & 7542 . & 51.21 & 2 & 4.22 & 8.45 & 2 & 44 & 20 & 1.76 & 61.42 \\
\hline 3 & 6.78 & 2 & 7542.00 & 102.42 & 3 & 4.22 & 12.67 & 2 & 44 & 20 & 1.76 & 116.85 \\
\hline 4 & 6.79 & 2 & 7542.00 & 102. & 3 & 4.22 & 12.67 & 2 & 44 & 2 & 1.76 & 116.85 \\
\hline 5 & 6.79 & 2 & 7542.00 & 102.42 & 4 & 4.22 & 16.89 & 2 & 44 & 20 & 1.76 & 121.07 \\
\hline 6 & 6.79 & 2 & 7542.00 & 102.42 & 5 & 4.22 & 21.12 & 2 & 44 & 20 & 1.78 & 125.30 \\
\hline 7 & 6.79 & 3 & 7542.00 & 153.63 & 4 & 4.22 & 16.89 & 2 & 44 & 20 & 1.76 & 172.28 \\
\hline 8 & 6.79 & 3 & 7542.00 & 153.63 & 3 & 4.22 & 12.67 & 2 & 44 & 20 & 1.76 & 168.06 \\
\hline 9 & 6.79 & 4 & 7542.00 & 204.84 & 6 & 4.22 & 25.34 & 2 & 44 & 20 & 1.76 & 231.94 \\
\hline 10 & 6.79 & 5 & 7542.00 & 256.05 & 7 & 4.22 & 29.56 & 2 & 44 & 20 & 1.76 & 287.37 \\
\hline
\end{tabular}

At the end of year 10 the system is replaced. This results in an additional cost of $31000 \times \$ 300 / f t=\$ 9,300 \mathrm{~K}$. Thereafter the installation experiences a significant reduction in: normal distribution heat loss, \# boiling manholes, \# leaks

The ongoing expense of implementing this technology (Column D) consist only of inspection calculated as 2 man-hours per manhole per year, at $\$ 20 /$ man-hour for 44 manholes $=\$ 1,760$. In the ROI spreadsheet this has been rounded up to $\$ 2,000$ to include incidentals and any recoating touch-ups needed. In addition to the avoided costs detailed above, the over-and-above savings of this technology (included in Column E) are conservatively estimated at $\$ 1 \mathrm{~K} / \mathrm{yr}$ for not having to instead run space heaters and/or rent portable boilers, possibly for multiple buildings, to provide altemate sources of space heating and/or domestic hot water in the event of a service intenuption

The estimated number of leaks is meant to be representative and is here chosen to be generally increasing toward the end of the useful life of a heat distribution system while still retaining some variability.

No attenyt has been made to estimate impacts on productivity, morale, or training hours. As well, energy costs are here assumed to be constant with a well documented and conservative value being chosen. Altematively, if a more complete analysis were to be done using the latest energy escalation factors (projected rising energy costs over and above that of inflation/discount rate) for the southeast region the expected result would be to slightly increase the curent ROI estimate. 


\section{Supporting Notes for ROI Calculation for Ft Jaclson HDS}

Ft. Jackson has at least 31,000-ft of direct buried (DB) hent distribution system (HDS) pipingt. These were installed in the 1986-1988 time frame as follows:

Phase I (2200 block): 13,500 -ft DB, completed 29 AUG 86

Phase II ( 3200 block): 6,500 -ft DB, completed 27 JAN 88

Phase III ( 4200 block): 11,000 -ft DB, completed 26 FEB 87

The typical approsimste replocement cost, in 2004 dollass, is $\$ 300$ / ft. Without the application of this corrosion prevertion technology a replacement is projected to be needed in 10 years time. In current dollars this would be a total of $\$ 9.3 \mathrm{M}$

Assuming a conservative average of 500 -ft. of trumk line and 200 -ft. of "take off" to feed one or more buildings per manhole, this implies a total of 44 manholes. As existing, origival system degrades some small but significant unmber of these monholes will flood and proceed to boil. As described in detail in an applicable Technical Report' ench of these can lose $\$ 51 \mathrm{~K}$ yr. It is worth noting that this valve is derived using an energy cost from FY94 of jast $\$ 6.79$ per MBtu. If recent history is any guide a more representative value is likely to incrense. In the calculation of this ROI nyy ongoing elevated heat loss, over and above acceptable designed transmission losses, of conduit sections between nonholes is not accounted for here. However, a heat distribution system is a complicated collection of interacting components where the effects of a local failure can cause adverse effects throughout the system. To better understnad these interactions plense see the referenced ERDC/CERI Technical Report'. The value used for leak repair is a documented value' from Ft. Jackson and is in 1991 dollars. The appropriate section of the conference paper is reproduced below.

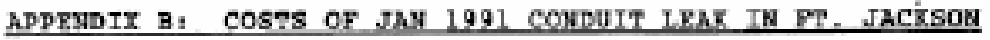

The leak occurred in the high temperature hot water prefabricated barled conduit line at the 5400 bleek on 1 Jan 1991 . The repair arew began work at 7 io0 an and did not atop until $3: 30$ an early the next morning. In order to find the leak 13 holea ( 5 in asphalt, $t$ in soil) vere dug ouing to a long pipe run eron the cantral energy plant nunber 2 to the nanhole serving the first buflding.

Location and repair:

thros vorknes at 22 houra $\ldots \ldots \ldots \ldots \ldots \ldots \ldots \ldots+1,128$

one vorknan at 10 hearg.................. 296

one supervisor at 21 hours................ 495

three truoks and two backhces............... 224

pateh bole in condult................... 300

Patch asphalt and $\mathrm{ri11}$ : asphalt naterial........................\$ 400

6 Letter Repert by NOMD \&e Associztos dated 17 Nerember, 1995

7 "Boiling Mothole Hest-Loss Calculztious", Marsh, Lz"zghton, US.ACERL Tochuiczl Report $98 / 62$ (Jee 1998).

\& "Condition Prediction Modal and Componeut Intoraction Fault Tres for Hezt Distribution Systems", Marsh, Temple, Kim, ERDC CERL TR-01-35 (July 2001).

Cevler Marsh, "Losseus Lezued to Date From tee Ft. Jackson, SC FEAP Hezt Distribution Systams Demoustration Project", Corps of Enginsers Flactrical and Mechemical Trainieg Confareuca, Dallas, TX, Jely 1992. 


\section{Appendix B: Test Panel Results}

Test panels using different primers were placed in three separate pits. Figures B1 - B3 show the result of exposure for 4,8 , and 12 months. Table B1 summarizes the coating details, location and exposure time for all test samples used.

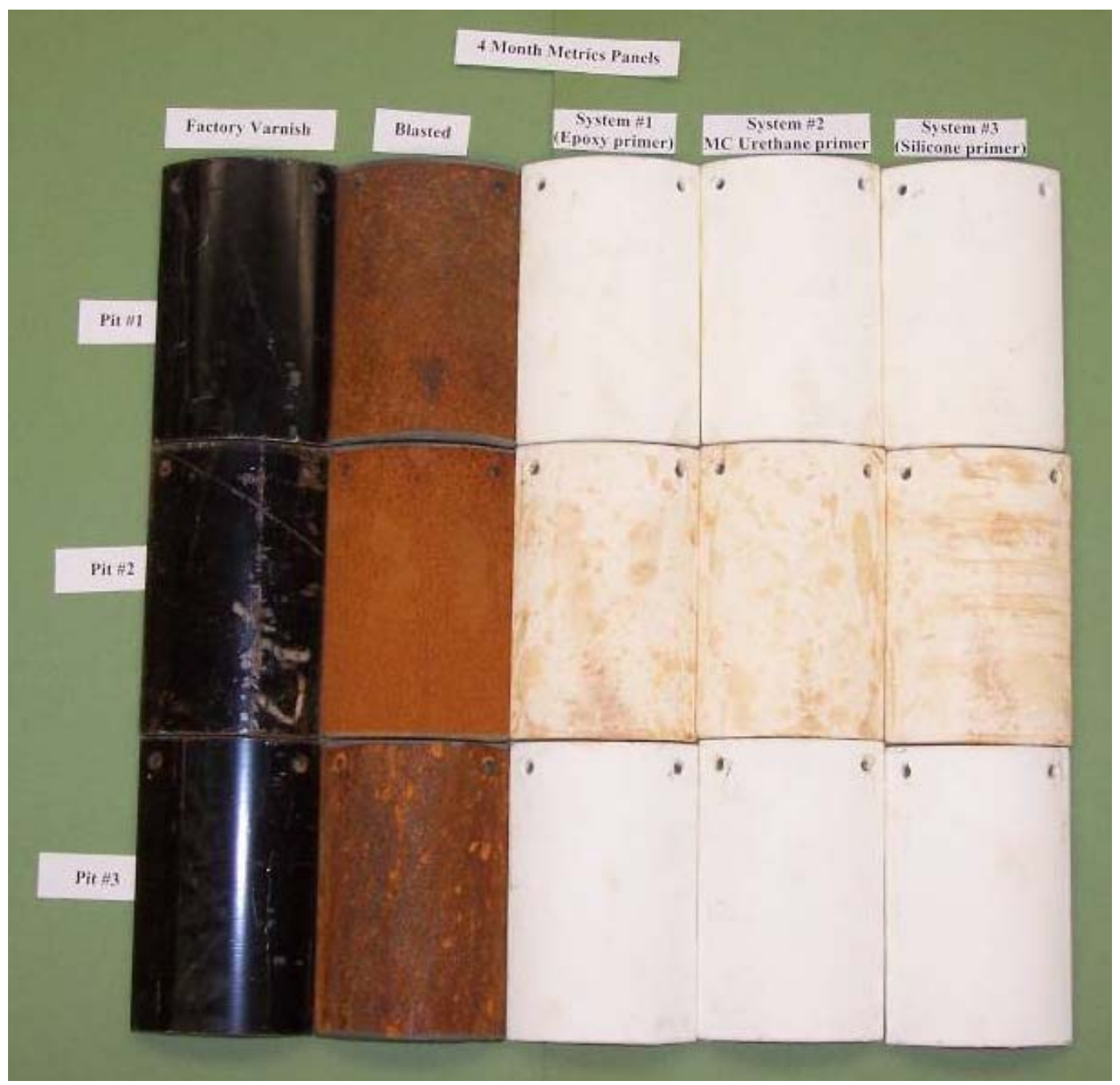

Figure B1. Samples showing results after 4 months of exposure in three separate pits. The vertical columns, left to right, are factory varnish, blasted, System \#1 (Epoxy primer), System \#2 (MC Urethane primer), and, System \#3 (Silicone primer). 


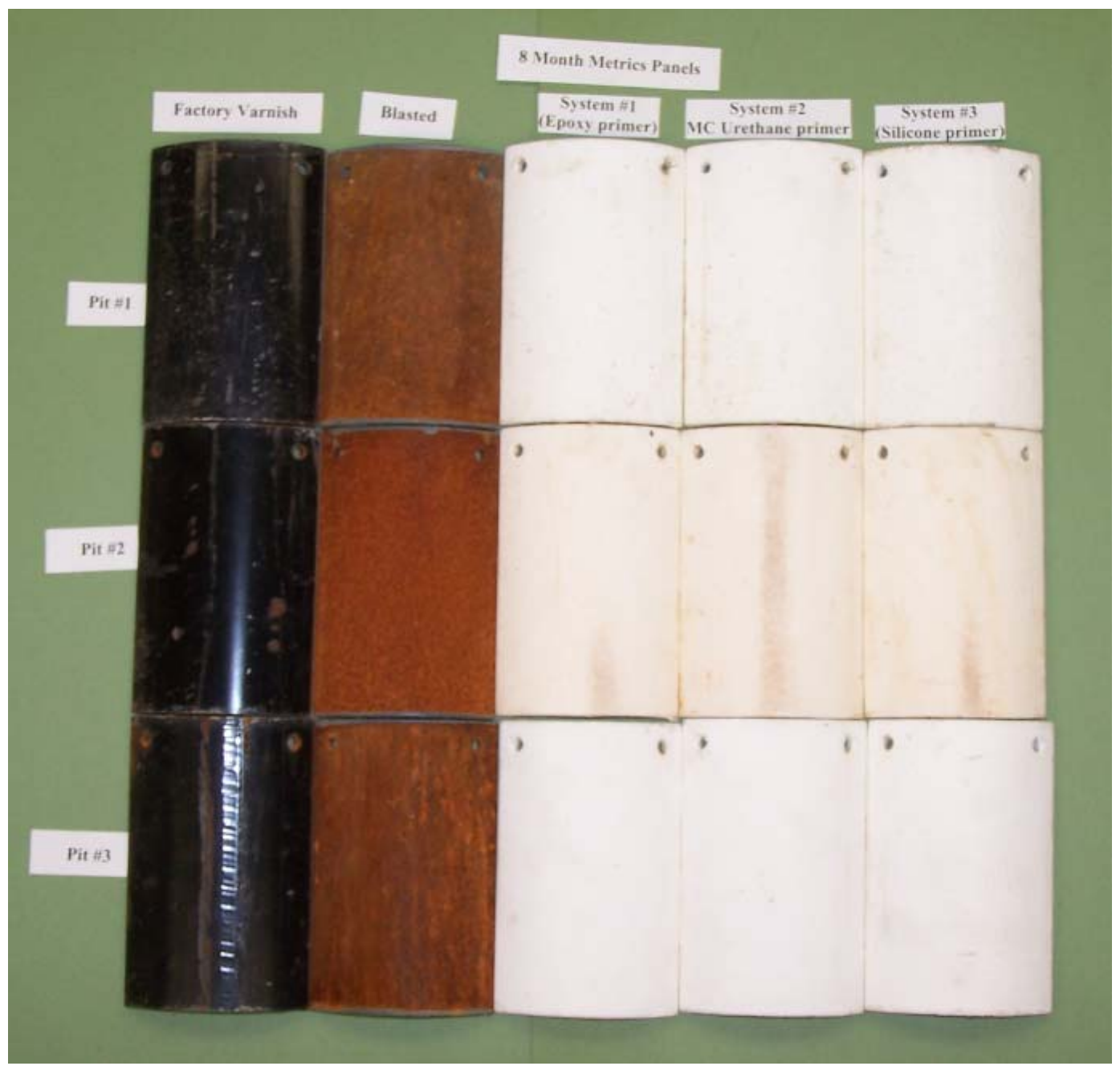

Figure B2. Samples showing results after 8 months of exposure in three separate pits. The vertical columns, left to right, are factory varnish, blasted, System \#1 (Epoxy primer), System \#2 (MC Urethane primer), and, System \#3 (Silicone primer). 


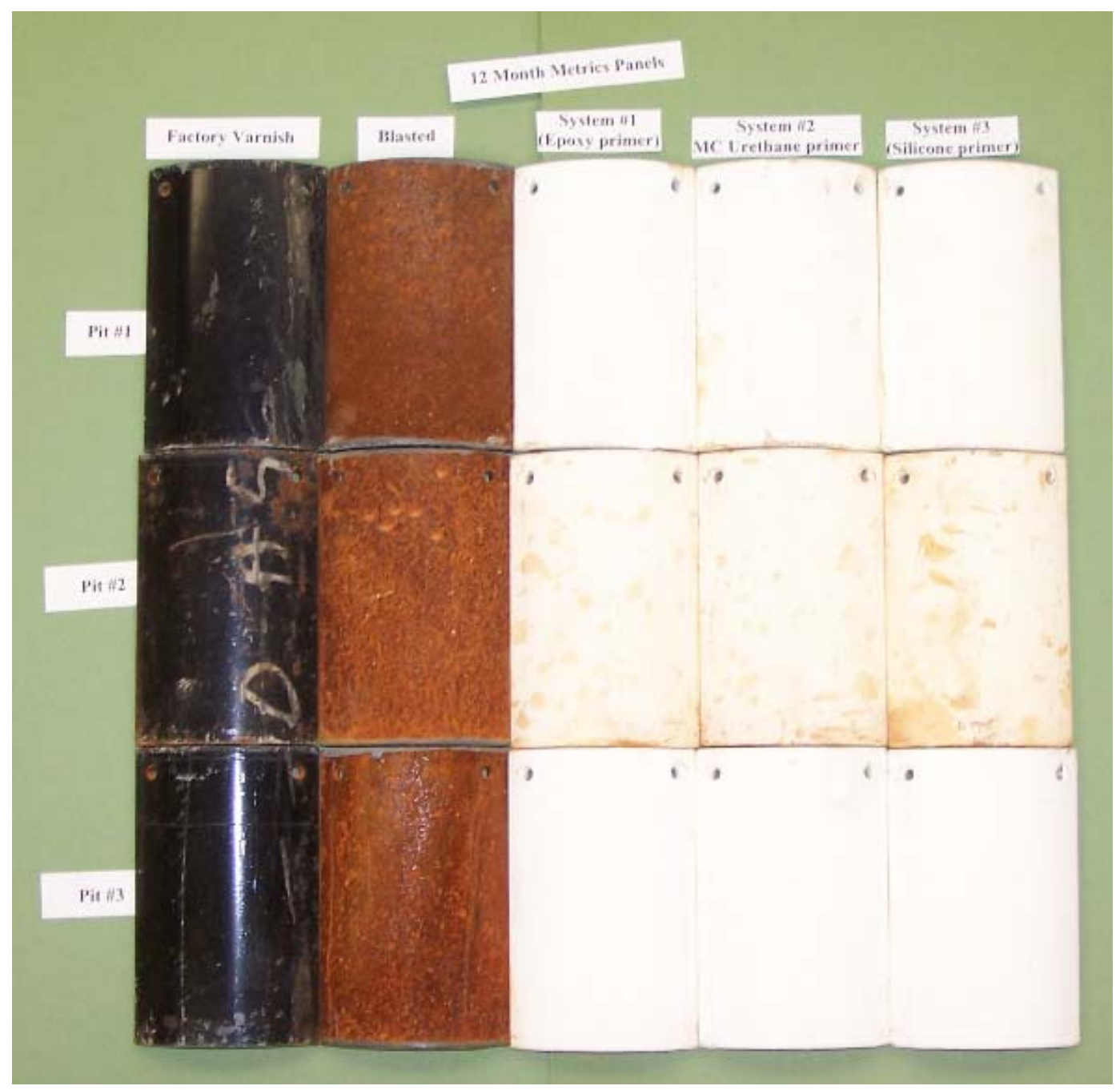

Figure B3. Samples showing results after 12 months of exposure in three separate pits. The vertical columns, left to right, are factory varnish, blasted, System \#1 (Epoxy primer), System \#2 (MC Urethane primer), and, System \#3 (Silicone primer). 
Table B1. Test panel locations, coating system, and duration of exposure.

\begin{tabular}{|c|c|c|c|c|c|}
\hline Panel \# & Primer & Midcoat & $\begin{array}{l}\text { Topcoat (total } \\
\text { system) }\end{array}$ & Location & $\begin{array}{l}\text { Exposure time } \\
\text { (Months) }\end{array}$ \\
\hline & 20-Jul-05 & 21-Jul-05 & 5-Aug-05 & & \\
\hline 0 & Factory Varnish & & & 1 & 12 \\
\hline 1 & Factory Varnish & & & 1 & 8 \\
\hline 2 & Factory Varnish & & & 1 & 4 \\
\hline 3 & Factory Varnish & & & 2 & 4 \\
\hline 4 & Factory Varnish & & & 2 & 8 \\
\hline 5 & Factory Varnish & & & 2 & 12 \\
\hline 6 & Factory Varnish & & & 3 & 8 \\
\hline 7 & Factory Varnish & & & 3 & 12 \\
\hline 8 & Factory Varnish & & & 3 & 4 \\
\hline 9 & Factory Varnish & & & Not in test & \\
\hline 10 & Bare & & & 1 & 12 \\
\hline 11 & Bare & & & 1 & 8 \\
\hline 12 & Bare & & & 1 & 4 \\
\hline 13 & Bare & & & 2 & 12 \\
\hline 14 & Bare & & & 2 & 8 \\
\hline 15 & Bare & & & 2 & 4 \\
\hline 16 & Bare & & & 3 & 8 \\
\hline 17 & Bare & & & 3 & 4 \\
\hline 18 & Bare & & & 3 & 12 \\
\hline \multirow[t]{2}{*}{19} & Bare & & & Not in test & \\
\hline & $\begin{array}{l}\text { MIL-DTL 24441(F159) 2- } \\
3 \text { mils }\end{array}$ & & & & \\
\hline 20 & & 20 & $36-55$ & 1 & 12 \\
\hline 21 & & 22 & $47-51$ & 1 & 8 \\
\hline 22 & & 23 & $41-61$ & 1 & 4 \\
\hline 23 & & 22 & $45-51$ & 2 & 12 \\
\hline 24 & & 20 & $43-57$ & 2 & 8 \\
\hline 25 & & 19 & $41-58$ & 2 & 4 \\
\hline 26 & & 27 & $46-73$ & Not in test & \\
\hline 27 & & 25 & $39-54$ & 3 & 8 \\
\hline 28 & & 18 & $44-53$ & 3 & 12 \\
\hline \multirow[t]{2}{*}{29} & & 24 & $37-45$ & 3 & 4 \\
\hline & MCzinc (2-3) mils & & & & \\
\hline 30 & & 18 & $33-61$ & Not in test & \\
\hline 31 & & 19 & $35-41$ & 1 & 12 \\
\hline 32 & & 18 & $38-47$ & 1 & 8 \\
\hline
\end{tabular}




\begin{tabular}{|l|l|l|l|l|l|}
\hline Panel \# & Primer & Midcoat & $\begin{array}{l}\text { Topcoat (total } \\
\text { system) }\end{array}$ & Location & $\begin{array}{l}\text { Exposure time } \\
\text { (Months) }\end{array}$ \\
\hline 33 & & 22 & $52-61$ & 1 & 4 \\
\hline 34 & & 20 & $43-46$ & 2 & 12 \\
\hline 35 & & 20 & $38-53$ & 2 & 8 \\
\hline 36 & & 22 & $40-58$ & 2 & 4 \\
\hline 37 & & 20 & $42-57$ & 3 & 8 \\
\hline 38 & & 22 & $39-51$ & 3 & 12 \\
\hline 39 & & 22 & $39-67$ & 3 & 4 \\
\hline & Hi Temp (2-3 mils) & & & & \\
\cline { 1 - 4 } & & 20 & $37-49$ & Not in test & \\
\hline 40 & & 20 & $50-68$ & 1 & 12 \\
\hline 42 & & 20 & $42-55$ & 1 & 8 \\
\hline 43 & & 21 & $38-59$ & 1 & 4 \\
\hline 44 & & 18 & $47-64$ & 2 & 12 \\
\hline 45 & & 19 & $44-57$ & 2 & 8 \\
\hline 46 & & 19 & $44-55$ & 2 & 4 \\
\hline 47 & & 22 & $44-55$ & 3 & 8 \\
\hline 48 & & 21 & $38-55$ & 3 & 12 \\
\hline 49 & & 22 & $50-54$ & 3 & 4 \\
\hline
\end{tabular}

The test panels were prepared as indicated below:

\section{Panels Number 0-9}

Rear blast \& paint only

MIL-DTL-24441 system

(3 mil each)

Front - no-blast no-paint

\section{Panels Number 10- 19}

Blast all surfaces

Rear paint

MIL-DTL-24441 system

(3 mil each)

Front no-paint 


\section{Panels Number 20- 29}

Blast all surfaces

Paint rear

MIL-DTL 24441 system

(3 mil each)

Paint front with MIL-DTL 24441(F159) 2-3 mils

Front second coat Ceramic 45 mils

\section{Panels Number 30- 39}

Blast all surfaces

Paint rear

MIL-DTL 24441 system

(3 mil each)

Paint front with MCzinc (2-3) mils

Front second coat Ceramic 45 mils

\section{Panels Number 40- 49}

Blast all surfaces

Paint rear

MIL-DTL 24441 system

(3 mil each)

Paint front with Hi Temp (2-3 mils)

Front second coat Ceramic 45 mils 


\section{Appendix C: Third-Party ROI Report}

\section{Economic Analysis \\ of the \\ Heat Distribution System Ceramic Paint Coating}

Submitted to

US Army Engineer Research and Development Center US Army Construction Engineering Research Laboratory

ATTN: Dr. Charles Marsh

2902 Newmark Drive

Champaign, Illinois 61822-1076

By

The PERTAN Group

44 Main Street, Suite 403

Champaign, Illinois 61820-3636

May 12, 2006

Final Report 


\section{Executive Summary}

Underground Heat Distribution Systems are critical to support the installation mission at many US Army garrisons. Current maintenance and repair practices reduce their service life considerably. This analysis compares the costs and benefits of an alternative coating method with those of the status quo practice. The alternative maintenance methodology contemplates coating the carrier pipes inside the manholes with a coat of corrosion protection primer paint and two coats of ceramic based paint. The economic analysis found that the ceramic coating alternative has a net saving of $\$ 63,366$ per manhole over a 20-year life cycle and a Savings to Investment Ratio of 58 . However, the analysis also found that it takes 16 years to recover the initial investment, and that the energy loses of the ceramic coating alternative are considerably higher than those of the status quo alternative. Finally, this report recommends adding insulation to the ceramic based paint to save energy.

\section{Introduction}

\section{Background}

Many U.S. Army installations rely upon central district Heat Distribution Systems (HDSs) to provide heating and hot water to their facilities. Fort Jackson has identified HDS as a critical part of the infrastructure to support the installation mission. HDSs are large complex systems made up of numerous components highly interdependent on one another. The deterioration of one component affects the performance and deterioration rate of other nearby components.

Manholes in a HDS house many of the critical components and also connect the different pipe sections of the system. The environment inside the manholes is often hot and humid and hence conducive to corrosion. Carrier pipes inside manholes are usually wrapped with insulation to prevent heat losses and protect service personnel entering the manhole. Water enters the manholes from leaking valves, rain, and ground water ingress. The water then gets trapped into the insulation and in between the insulation and the pipe. This condition makes the corrosive environment around the carrier pipe more severe and speeds the deterioration of the carrier pipe. 
The corrosion of the carrier pipe in the manholes has a ripple effect though the other components in the same manhole and the connecting pipes ${ }^{1}$. Protecting the carrier pipe inside the manholes against corrosion extends the service life of the entire HDS considerably. It is then desirable to have a cost effective coating alternative able to protect the carrier pipes against corrosion while keeping the outside temperature of the pipes low enough to protect service personnel entering the manhole.

\section{Objective}

The objective of this analysis is to provide quantitative documentation of economic Return on Investment (ROI) performance of the heat distribution system coating system that will be installed at Fort Jackson, SC.

\section{Approach}

This analysis follows the seven-step process outlined in the Department of the Army Economic Analysis (EA) Manual and recommended by DODI 7041.3. The process is depicted in Figure $\mathrm{C} 1$ below. These seven steps are divided into four major categories: Study Formulation, Determine Costs and Benefits, Perform Analysis, and Report Results.

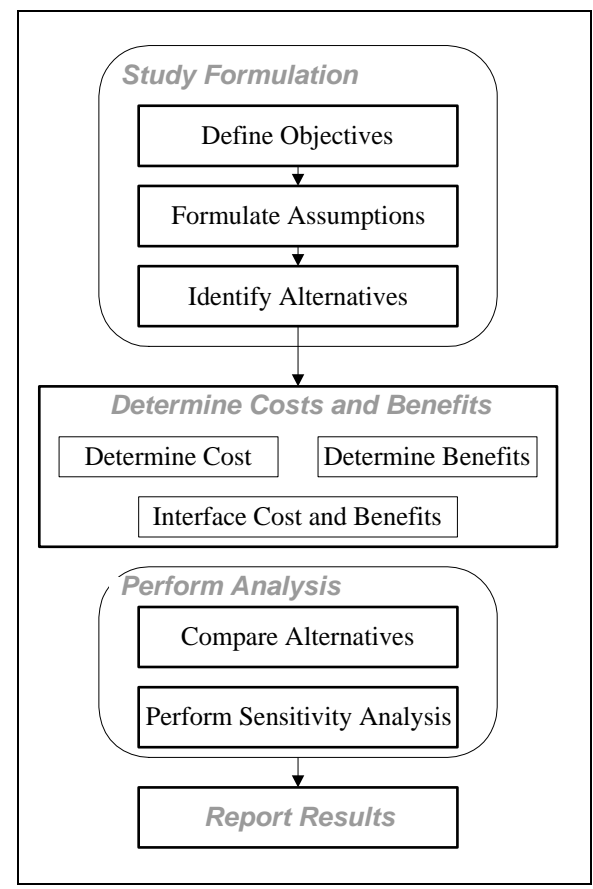

Figure $\mathrm{C} 1$. Economic analysis process.

\footnotetext{
1 Underground Heat Distribution Systems; Robert O. Couch, Ricwil Piping Systems; 1993 Federal Section Comference; IDCA; May 20-21, 1993; Arlington, VA;.
} 


\section{Study Formulation}

The first three steps of the Economic Analysis process involve the formulation of the study. They are: Definition of Objectives, Formulation of Assumptions, and Identification of Alternatives.

\section{Determine Costs and Benefits}

This step of the Economic Analysis (EA) process is the determination and estimation of the different costs and benefits of each alternative. It involves the selection of the different cost elements involved and the gathering of the corresponding values.

\section{Perform Analysis}

The next two steps of the AIS EA Handbook involve (1) the evaluation and comparison of the different alternatives according to the costs and benefits obtained before and (2) performance of a sensitivity analysis.

\section{Report Results}

The final step of the EA process is the reporting of the results. This step involves documenting all estimates and explaining recommendation(s).

\section{Scope}

This study is an economic analysis, not a budget analysis. Economic analysis and budget analysis are different processes. While an economic analysis is used for determining the most cost-effective alternative that meets an organization's requirement, a budget analysis provides an organization with the total cost impact of an alternative. The data presented in an economic analysis may or may not be useful in a future budget process. Some costs are omitted from the economic analysis because they are wash costs (a cost that is identical for all alternatives). Also, some costs included in the economic analysis may refer to several organizations, making it difficult to use them in the budgeting process.

\section{Mode of Technology Transfer}

The recommendation of this report will be used to specify corrosion protection treatment in Heat Distribution Systems. 


\section{Study Formulation}

\section{Definition of Objectives}

This is the first step of the EA and also the most important. A clear and concise objective will set the boundaries of the study and will define the goal to be accomplished in measurable terms. Clearly, an improperly stated objective will lead to an improper solution.

\section{Problem}

Carrier pipes in the manholes of HDS are routinely exposed to a corrosive environment of humidity and heat. That corrosive environment is exacerbated by leaking valves, ground water ingress, and occasional manhole flooding. Current corrosion protection systems aim to protect the conduit pipe. Moreover, current design/construction practices wrap insulation around the carrier pipes in the manhole to prevent heat loses and to protect maintenance personnel working in the manhole from high temperature pipes. However, after the manhole is flooded, insulation traps moisture around the carrier pipe and speeds up corrosion.

\section{Project Objective}

The objective of this project is to identify an alternative to the current practice of wrapping insulation around pipes. The alternative should be cost effective and provide a better corrosion protection without compromising safety.

\section{Formulation of Assumptions}

In order to perform an EA, several assumptions about future events need to be made. Following is the list of assumptions used in this analysis:

- The start year of the analysis is FY-2005.

- The lead-time (period extending from the start year to the completion of installation) is 1 year. At the end of the first year all 100\% of the benefits are achieved.

- The period of analysis is 20 years.

- The real discount rate is $4 \%$.

- Cost elements for each alternative are estimated using an average manhole. The average manhole is $10 \mathrm{ft}$ by $10 \mathrm{ft}$ and has two pipelines in it, supply and return. Inside the manhole there is a $\mathrm{T}$ in each line and a 


\section{Identification of Alternatives}

Currently, underground direct buried drainable dryable steel conduit HDS are protected against corrosion by several means. The soil-side surface of the conduit pipe is protected by a special coating and/or cathodic protection. The interior side of the carrier pipe is protected by chemical water treatment performed continuously at the central plant. Corrosion in the annuli between the conduit pipe and the carrier pipe can be prevented by properly monitoring the moisture condition of this space through the drains and vents at the end plates inside the manholes. However, the sections of carrier-pipe inside the manholes are not well protected against corrosion. Those sections are wrapped with insulation and protected with an aluminum jacket. Moisture entering the manhole through the top gets trapped between the insulation and the outer side of the carrier pipe speeding up the corrosion process.

\section{Current Method (Status Quo) Alternative}

In this alternative, insulation is wrapped directly around the exterior side of the carrier pipe all through the section of pipe enclosed in the manhole. Current maintenance practices call for visual inspection of the insulation periodically and the substitution of the insulation when it is missing or highly deteriorated. However, this practice can not inspect the surface between the insulation and the pipe when the insulation is not missing even if it is saturated with moisture. Moreover, maintenance personnel shortages make the inspections unlikely and lack of maintenance funds make the insulation replacement prohibitive.

\section{Corrosion Protection Primer-Ceramic Paint Combination (P-CP)}

In this alternative, when the insulation is deteriorated, it is replaced by a ceramic paint instead of replacing it by a similar insulation. After removing the deteriorated insulation, the exterior side of the carrier pipe inside the manhole is first treated with a zinc based paint to protect against corrosion. Then, it is painted with a ceramic paint to insulate the pipes and protect workers entering the manhole from injuries due to high temperature pipes. 


\section{Cost and Benefits}

Determining the costs and benefits associated with each alternative is the fourth step of an EA. This part of the analysis focuses on the collection and the comparison of the costs of implementing each alternative and the benefits associated with each course of action. Two issues worth considering before estimating costs and benefits are (1) relevance of the cost element and (2) level of accuracy of the estimate.

When comparing alternatives, not all cost elements are necessarily used in the analysis. The goal of the economic analysis is to only determine the most cost-effective alternative to the government that meets the organization's requirement. The outcome of the analysis is a ranking of the two alternatives. Only the differential costs between alternatives are considered in the analysis. Cost elements that do not affect the order of the ranking and are common to all alternatives are not considered here. In other words, costs that are identical for both alternatives (wash costs) are excluded from the evaluation and only the relative differences between alternatives are developed and compared.

The same rationale applies to the level of accuracy that is required for the estimates to be relevant. Many of the estimates used in this analysis are expert opinions and are not expected to be $100 \%$ accurate. To test the impact of the estimates' accuracy on the final ranking, a sensitivity analysis is performed after comparing cost and benefits. That analysis tests what changes in assumed values are necessary to impact the final ranking of the alternative.

\section{Relevant Cost Elements}

There are five Cost Elements that capture the economic differences relevant to selecting the most cost-efficient maintenance alternative. They are Initial Investment, Preventive Maintenance, Corrective Maintenance, Energy Consumption, and Salvage Value. Following is a description of each cost element and how they impact the total cost.

1. Initial Investment. This is the total investment cost required to implement each maintenance alternative. For this analysis, there is not any initial investment for the status quo alternative. However, for the PrimerCeramic Paint combination ( $\mathrm{P}-\mathrm{CP})$ alternative, the initial investment is the 
cost of removing deteriorated insulation, sanding the pipes inside the manhole, applying the primer, and applying two coats of ceramic paint.

2. Preventive Maintenance (PM). This cost element captures the cost of doing PM on the carrier pipe inside the manhole. For this analysis, the preventive maintenance includes the cost of performing periodic inspections of the carrier pipe. Under the status quo alternative, the periodic inspections are more difficult than those of the $\mathrm{P}-\mathrm{CP}$ because the insulation covers the pipe and hence gets in the way of detecting leaks in the carrier pipe. However, the costs of these inspections are considered wash costs in the analysis. The inspections are very similar under both alternatives.

3. Corrective Maintenance (CM). This cost element captures the cost of activities involving breakdown maintenance, including materials and investigative time to determine the cause of a failure or incident. For the Status Quo alternative, it includes the cost of repair by replacement. Under the Status Quo alternative, the life of the HDS is 16 years ${ }^{1}$. That is the number of years that takes the Condition Index (CI) of a direct buried drainable dryable HDS fall below 25\%. At that point the system is beyond repair and has to be replaced - Repair by replacement.

Under the Primer-Ceramic Paint (P-CP) combination alternative, the time for the CI to fall below $25 \%$ is more than 30 years. That is so because protecting the carrier pipe inside the manhole against rust prevents leaks and extra moisture in the manhole which in turn prevents flooding of the manhole. Flooding of manholes is the main cause of failure for HDS² and increases the stress in the pipe segments entering the manhole considerably. In other words, the prevention of leaks in the manhole makes the conditions inside the manhole similar to those of inside manholes with cover raised. The CI for direct buried drainable dryable HDS with raised covers in the manholes, after 30 years is $60 \%$ - Good Condition.

4. Energy Consumption. This cost element captures the cost of energy lost in the pipe inside the manhole for each alternative. It is included in the analysis to identify any energy saving or extra cost associated with the $\mathrm{P}-\mathrm{CP}$ combination. The energy cost is estimated by assuming that the

\footnotetext{
1 Engineering Management System For Heat Distribution System; NMD and Associates; Alexandria, VA; August 1995

2 Underground Heat Distribution Systems, 1993 Federal Section Conference; May 20-21, 1993; Arlington, VA
} 
boiler plant has an Efficiency Factor (EF) of 0.8 and that the cost of natural gas to the installation is $\$ 0.6$ per Therm.

5. Salvage Value. This cost element represents the value of the HDS at the end of the analysis period. Under the Status Quo alternative, at the end of the 20 year analysis the buried pipe still has 12 years of economic life left -16 years less 4 years. Under the P-CP combination alternative, at the end of the 20 years analysis, the buried pipe still has more than 10 year of economic life left -30 years less 20 years. Since the economic life left under both alternatives are very similar, the salvage value is a wash cost.

Table $\mathrm{C} 1$ below summarizes the above cost element for each alternative

Table C1. Summary of Cost Elements.

\begin{tabular}{|l|l|l|}
\hline Cost Elements & Status Quo & Prime-Ceramic Paint \\
\hline Initial Investment & No new equipment required & $\begin{array}{l}\text { Remove Insulation } \\
\text { Sand blast pipes } \\
\text { Apply Primer } \\
\text { Apply 1 } \text { st }^{\text {coat paint }} \\
\text { Apply 2 }{ }^{\text {nd }} \text { coat paint }\end{array}$ \\
\hline $\begin{array}{l}\text { Preventive } \\
\text { Maintenance }\end{array}$ & Null & Null \\
\hline $\begin{array}{l}\text { Corrective } \\
\text { Maintenance }\end{array}$ & $\begin{array}{l}\text { Replace Pipes in } \mathrm{MH} \\
\text { Replace Valves in } \mathrm{MH} \\
\text { Replace Pipe outside MH }\end{array}$ & None \\
\hline Energy Consumption & $\begin{array}{l}\text { Energy lost while insulation is } \\
\text { saturated with water + energy } \\
\text { lost while insulations is dry }\end{array}$ & $\begin{array}{l}\text { Energy lost through ceramic } \\
\text { paint. }\end{array}$ \\
\hline Salvage Value & Wash & Wash \\
\hline
\end{tabular}

\section{Source and Derivations of Cost and Benefits}

Initial Investment

Neither of the two alternatives considered here requires new equipment or training to be implemented. Therefore, the initial investment cost for both alternatives is $\$ 0$.

Under the P-CP combination alternative, applying the paint requires removing old insulation, sanding the pipes, applying the primer, and apply- 
ing two coats of the ceramic paint. The costs of those activities have two components labor and materials.

\section{Materials:}

1. Ceramic Paint

Ceramic Paint cost: $\$ 44.5 /$ Gallon

Paint Efficiency Rate for no less than 45 mils dry film $=16$ $\mathrm{SqFt} /$ Gallon

$30 \mathrm{ft}$ of pipe per manhole

4 in. internal diameter $=4.5$ external diameter $=4.5 \times 3.14 / 12=$ 1.177 Ft exterior circumference

Total pipe surface in a manhole $=1.177 \times 30=35.32 \mathrm{SqFt}$

Cost per manhole $=(35.32 \mathrm{SqFt} / 16 \mathrm{SqFt} / \text { Gallon })^{*} \$ 44.5$ Gallons $=$ $\$ 98.25$

Total Ceramic Paint Cost per manhole $=\$ 98.25$

2. Primer Paint

Primer Paint cost: \$50/Gallon

Paint Efficiency Rate for pipes for no less than 3 Mils dry film $=200$ $\mathrm{SqFt} / \mathrm{Gal}$

Total Primer Cost per manhole $=(35.32 \mathrm{SqFt} / 200 \mathrm{SqFt} / \mathrm{Gall}) \mathrm{x}$ $\$ 5 \mathrm{O} / \mathrm{Gall}=\$ 8.83$

Total Primer Cost per manhole $=\$ 8.83$

Total Materials Cost per $\mathrm{MH}=\$ 98.25+\$ 8.83=\$ 107.08$ 


\section{Labor:}

Last September 2005 at Fort Jackson, it took a crew of two people to perform the necessary activities to implement the P-CP alternative in three manholes four days. The labor included sanding the pipes, applying the primer and the two coats of paint.

$$
\begin{gathered}
\text { Labor Hours per } \mathrm{MH}=(4 \text { days } * 8 \text { Hours } / \text { Day * } 2 \text { person }) / 3 \mathrm{MH}= \\
21.3 \text { Hours }
\end{gathered}
$$

Hourly Labor Rate $=\$ 35 /$ Hour in $1996 \times 1.48$ escalation factor to

$$
2005=\$ 51.8 / \text { Hour }
$$

Labor Cost $=21.3$ Hours $\mathrm{x} \$ 51.8 /$ Hour $=\$ 1,103$ per $\mathrm{MH}$

\section{Initial Investment Cost:}

$$
\begin{aligned}
& \text { Initial Investment Cost }=\text { Labor Cost }+ \text { Material Cost } \\
& \text { Initial Investment Cost }=\$ 1,103+\$ 107.8=\$ 1,110
\end{aligned}
$$

Preventive Maintenance (PM)

Even though widely accepted preventive maintenance procedures ${ }^{1}$ recommend repairing the deteriorated insulation around the carrier pipes in the manholes, lack of manpower at the installations render the practice a low priority status. As a consequence, in order to make this analysis reflect the every day practice at the installation, the PM cost of repairing insulation under the Status Quo alternative is zero.

There is not any preventive maintenance requirement for the combination of primer and ceramic paint. Moreover, the expected life of the paint combination is 30-plus years. Therefore, the estimated cost of preventive maintenance for the $\mathrm{P}-\mathrm{CP}$ alternative is also zero.

\footnotetext{
1 Engineering Management System For Heat Distribution System; NMD and Associates; Alexandria, VA; August 1995
} 


\section{Corrective Maintenance}

Under the status quo alternative, the corrective maintenance activities required to repair failed pipes inside and out of the manhole:

- Remove Insulation

- Replace carrier pipes inside MH

- Replace valves inside MH

- Apply new insulation and protective jacket

- Replace buried pipe outside MH

For the average manhole the cost of replacing the insulation according to Engineered Management System for HDS Project Level, NMD and Associates: ( $1.48=$ escalation factor from 1996 prices to 2002 prices)

Cost to replace insulation $=30 \mathrm{ft}$ x $\$ 5.3 / \mathrm{ft} \times 1.48=\$ 235$

Under the Status Quo alternative, the life expectancy of the carrier pipe inside the manhole is considered to be only 15 years. After 15 years, the carrier pipes will present considerable pitting and have to be replaced. The cost of replacing the pipes inside the manhole is estimated using NMD report as follows:

From 1996 report the cost for replacing $10 \mathrm{ft}$ section pipe is = 2 Hours @ $\$ 35 /$ Hour $+\$ 178$ material $=\$ 247 / 10$ feet. Escalating those prices to 2005 and considering that there are $30 \mathrm{ft}$ pipe inside:

Preliminary estimate to replace pipe in $\mathrm{MH}=\$ 247^{*} 1.48 * 3=\$ 1,096$

The above estimate does not take into account the fact that the average manhole has 2 Ts and flanges for 2 Valves that also need to be replaced due to the pitting. It is estimated that the flanges and the Ts add complexity to the replacement and hence increases the cost by $50 \%$

Cost to replace pipe inside $\mathrm{MH}=\$ 1,096 \times 1.5=\$ 1,645$

The cost to replace the 2 valves form NMD and associates report and escalated to 2005 is:

Cost to replace Valves $=2 \times \$ 435 \times 1.48=\$ 1,288$ 
The cost to replace the direct buried pipe outside $\mathrm{MH}$ is also estimated using NMD report. The 1996 cost to replace 4 in. buried per liner $\mathrm{ft}$ is $\$ 101$. That cost does not include the cost involved in cutting through and then replacing grade level structures like parking areas, sidewalks, curves, and pavement. Considering that there are $500 \mathrm{ft}$ of supply and $500 \mathrm{ft}$ of return pipe, the minimum cost to replace the buried pipe at 2006 price level is:

Cost to replace buried pipe $=2 \times 500 \times 1.48 \times \$ 101=\$ 149,480$

The total corrective maintenance to replace insulation, pipes, valves, and buried pipes is then:

Total Corrective Maintenance Cost $=\$ 235+\$ 1,645+\$ 1,288+\$ 149,480$ $=\$ 152,648$

Energy Conservation

Under the Status Quo alternative, the pipes inside the manholes has 1.5 in. of mineral fiber insulation wrapped around the pipe and protected with an aluminum jacket with a conductivity factor of $0.024 \mathrm{Btu} / \mathrm{Hr}-\mathrm{Ft}-{ }^{\circ} \mathrm{F}$. Under the $\mathrm{P}-\mathrm{CP}$ alternative, the pipe has at least 45 mil of ceramic paint which has a thermal conductivity of $0.0563 \mathrm{Btu} / \mathrm{Hr}-\mathrm{Ft}-{ }^{\circ} \mathrm{F}$. Annex 1 contains detailed estimates of the cost of energy lost through the pipes in the manhole under each alternative. Under the Status Quo alternative, the estimated cost of the annual energy lost in the average manhole is $\$ 150$. Under the P$\mathrm{CP}$ combination alternative, the estimated cost of the annual energy lost in the average manhole is $\$ 1,392$.

\section{Residual Value}

The economic life left at the end of the period of analysis is similar under both alternatives. Hence, the residual value is a wash cost.

Table $\mathrm{C} 2$ below summarizes the estimated values for each cost component. 
Table C2. Summary of Cost Components.

\begin{tabular}{|l|l|l|}
\hline Cost Elements & Status Quo & Prime-Ceramic Paint \\
\hline Initial Investment & $\$ 0$ & $\$ 1,110$ \\
\hline Preventive Maintenance & $\$ 0$ & $\$ 0$ \\
\hline Corrective Maintenance & $\$ 152,648$ at year 16th & $\$ 0$ \\
\hline Energy Consumption & $\$ 150 /$ Year & $\$ 1,392 /$ Year \\
\hline Residual Value & Wash & Wash \\
\hline
\end{tabular}

\section{Comparing Cost and Benefits}

\section{Introduction}

The next two steps in the EA process are (1) the comparison of alternatives and (2) the performance of sensitivity analysis. Alternatives are compared and ranked using three methods: Net Present Value (NPV), Savings-toInvestment Ratio (SIR), and Discounted Payback Period (DPP). These comparisons were done using the ECONPACK 3.o computer program.

The NPV method is the standard way to compare alternatives in the Army when all the alternatives meet the requirements. The NPV is calculated for each alternative by discounting the value of the costs minus the benefits for each of the twenty years of the analysis and summing them up for a total net (current) value in today's dollars.

SIR is used only to compare investment cost to savings to determine if the investment cost can be recovered through the savings. It is the ratio of savings resulting from using an alternative, instead of using the status quo, to the investment required for implementing the new alternative. When computing SIR, total annual maintenance and operation costs are not discounted, only the difference between annual costs for the two alternatives.

Payback period is the time required for the total accumulating savings of an alternative to offset investment costs. DPP is used in conjunction with SIR. When the SIR is greater than 1, DPP answers the question "How long does it take to recoup the investment cost?" 


\section{Comparing Alternatives}

The costs estimated in the prior section were used to compute the Life $\mathrm{Cy}$ cle Cost of each alternative. Annex 2 contains the ECONPACK output file with the results of the analysis. Following is a summary of the results.

Life Cycle Cost of Status Quo

The Life Cycle Cost (LCC) per manhole of the Status Quo alternative over the 20-year period has a

- Cumulative Net Present Value of $\$ 81,916$

Life Cycle Cost of Corrosion Protection Primer-Ceramic Based Paint

The LCC per manhole of the Corrosion Protection Primer-Ceramic Based Paint alternative over the 20-year period has a

- Cumulative Net Present Value of $\$ 19,639$

- Present Value of Savings of $\$ 63,366$

- Present Value of the Initial Investment of $\$ 1,088$

- Savings to Investment Ratio of 58.2

- Discounted Payback Period of 16.2 Years

\section{Sensitivity Analysis}

Rankings of alternatives may change when some of the assumptions in the analysis change. To test the robustness of the above ranking a test of the sensitivity of the analysis to changes in the estimated savings was performed. The analysis showed that the ranking of alternatives was not sensitive to changes of plus or minus $100 \%$ in the cost of the energy losses of the ceramic paint alternative. Figure $\mathrm{C} 2$ shows the NPV of each alternative against percentage changes in the cost of energy losses. 


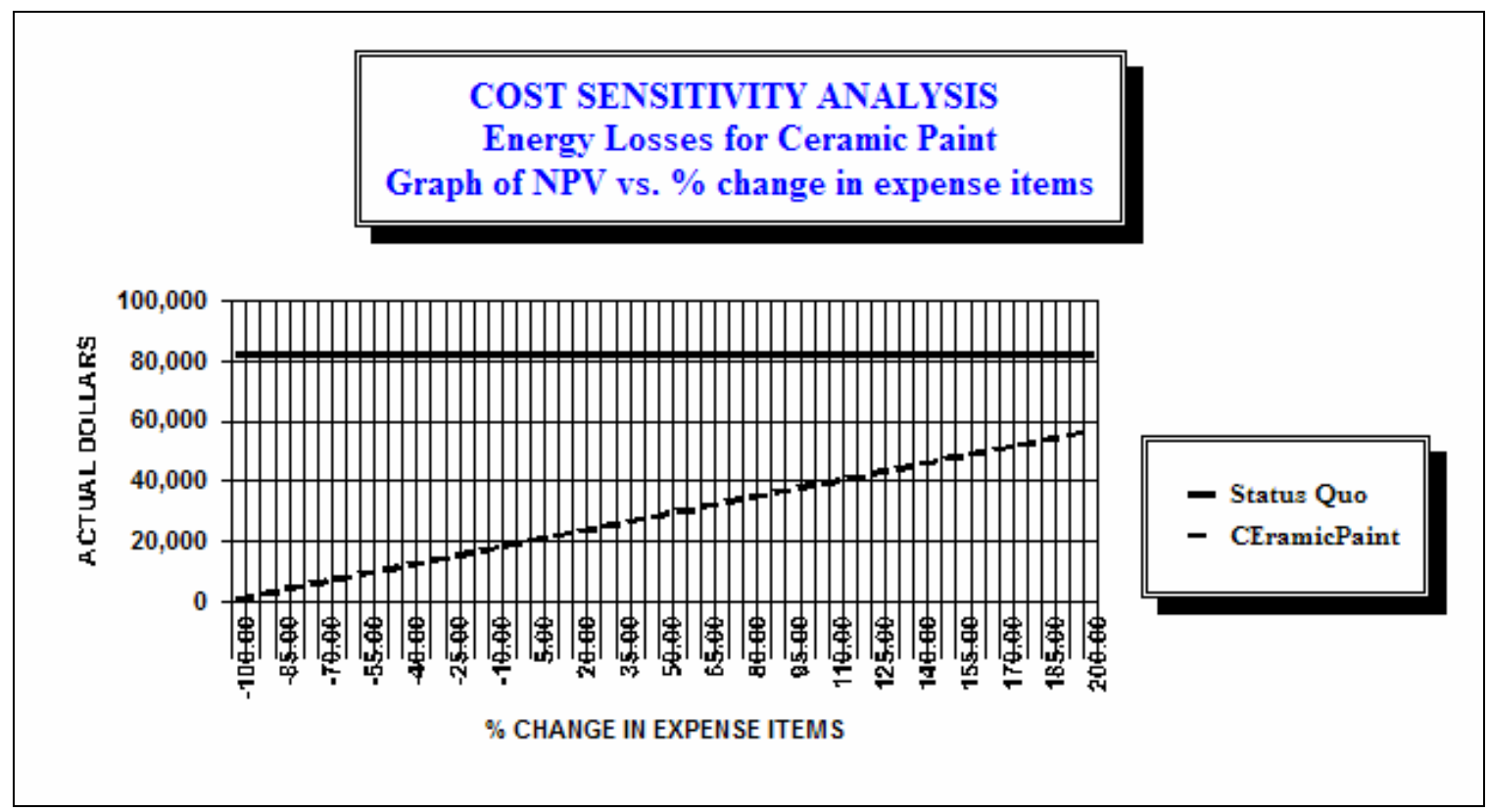

Figure C2. Energy Losses Sensitivity Analysis.

However, the analysis showed that the ranking of the alternatives was sensible to changes in the cost of the major repair of the Status Quo alternative. For the Status Quo alternative to become the least cost alternative, the cost of the major repair has to be reduced by $77.93 \%$. Figure $\mathrm{C}_{3}$ below, shows the NPV of each alternative against percentage changes in the cost of major repairs.

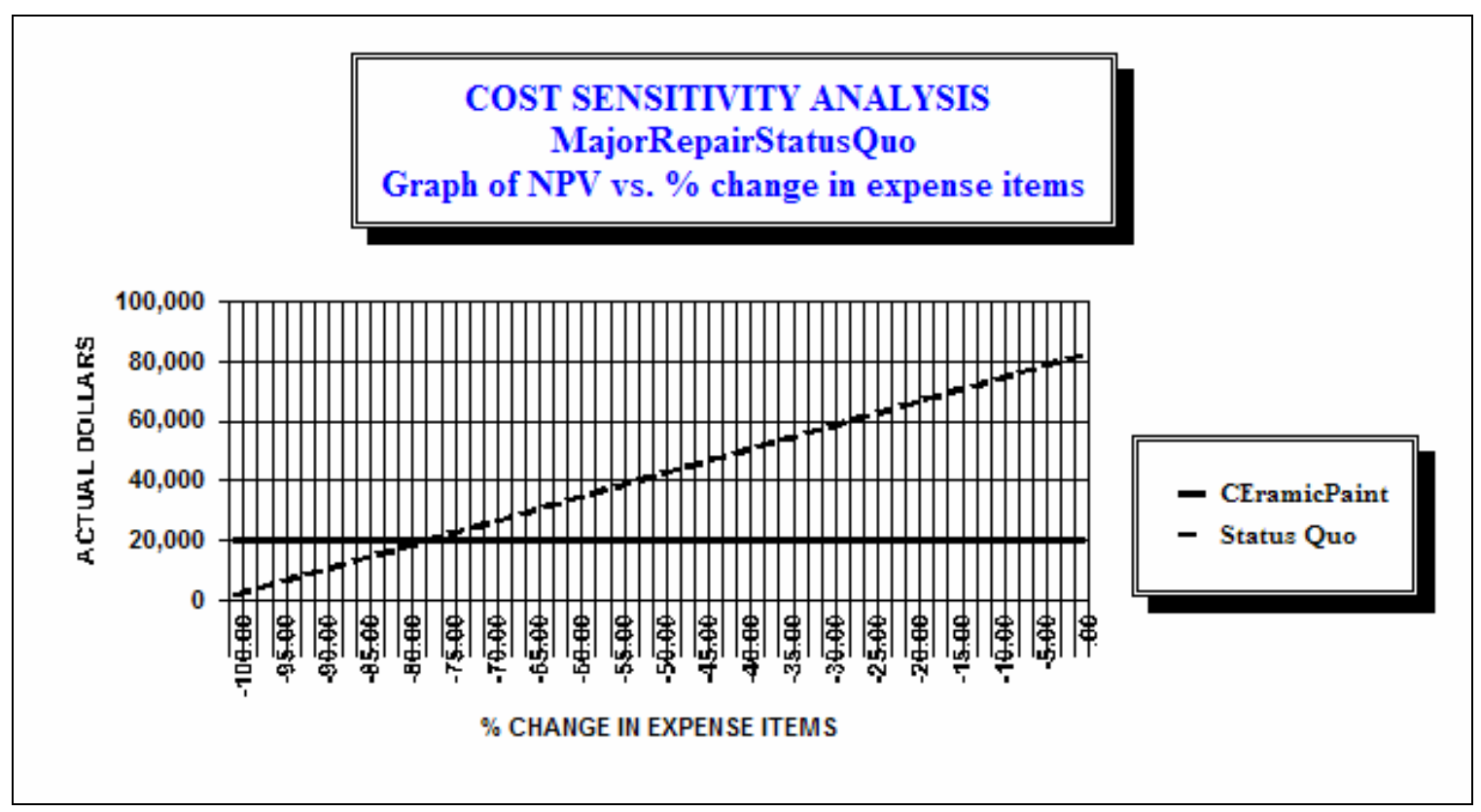

Figure C3. Pipe Replacement Cost Sensitivity Analysis. 


\section{Conclusions and Recommendations}

\section{Conclusion}

An economic analysis of an alternative method of maintaining and repairing the manholes of underground drainable dryable heat distribution systems was performed. The alternative maintenance methodology contemplates coating the carrier pipes inside the manholes with a corrosion protection primer paint and two coats of ceramic based paint. The economic analysis found that the ceramic coating alternative has a net savings of $\$ 63,366$ per manhole over a 20-year life cycle and a Savings to Investment Ratio of 58 . However, the analysis also found that it takes 16.2 years to recover the initial investment. In addition, the energy analysis also found that the energy loses of the ceramic coating alternative are considerably higher than those of the Status Quo alternative.

\section{Recommendations}

Energy conservation is currently a high priority national policy. As a consequence, it may not be politically correct to recommend an alternative that uses more energy than the status quo. Therefore, it is recommended that regular insulation be added on top of the ceramic paint to save energy.

\section{Annex 1: Energy Lost Though Carrier Pipes at Manhole}

\section{Heat Transfer}

The equations governing the amount of heat transferred through the walls of a pipe by conduction are derived from the Fourier's Law of Conduction ${ }^{1}$. For a rectangular wall, the equation is:

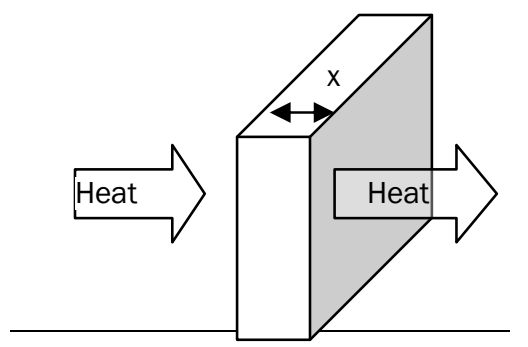

$$
\dot{Q}=k \times A \times\left(\frac{\nabla T}{\nabla x}\right)
$$

Equation $\mathrm{C} 1$

1 DOE Fundamentals Handbook; Thermodynamics, Heat Transfer, and Fluid Flow, Volume 2 of 3; U.S. Department of Energy; Washington, D.C. 20585; June 1992; Page 6. 
For a cylinder, the equation is:

$$
\dot{Q}=k A\left(\frac{\nabla T}{\nabla r}\right) \quad \text { Equation } \mathrm{C} 2
$$

where:

$\dot{Q}=$ rate of heat transfer $(\mathrm{Btu} / \mathrm{hr})$

$\mathrm{A}=$ cross-sectional area of heat transfer $\left(\mathrm{ft}^{2}\right)$

$\Delta \mathrm{x}=$ thickness of slab $(\mathrm{ft})$

$\Delta \mathrm{r}=$ thickness of cylindrical wall $(\mathrm{ft})$

$\Delta \mathrm{T}=$ temperature difference $\left({ }^{\circ} \mathrm{F}\right)$

$\mathrm{k}=$ thermal conductivity of slab, or of pipe wall $\left(\mathrm{Btu} / \mathrm{ft}-\mathrm{hr}-{ }^{\circ} \mathrm{F}\right)$

For a pipe with insulation wrapped around, the Fourier's Law has the form ${ }^{1}$ :

$$
\frac{\dot{Q}}{L}=\frac{2 \pi\left(T_{m}-T_{o}\right)}{\left[\frac{\ln \left(\frac{r_{2}}{r_{1}}\right)}{k_{s}}+\frac{\ln \left(\frac{r_{3}}{r_{2}}\right)}{k_{a}}\right]}
$$

Where:

$r_{1}=$ Inside radius of carrier pipe

$r_{2}=$ Outside radius of carrier pipe and inside radius of insulation

$r_{3}=$ Outside radius of insulation

$k_{s}=$ Conductivity of steel

$k_{a}=$ Conductivity of insulation

$\mathrm{T}_{\mathrm{m}}=$ Inside temperature of the pipe

$\mathrm{T}_{\mathrm{o}}=$ Outside temperature of the insulation

To estimate the annual cost of the energy lost through the pipe under both scenarios the following assumptions were made for the average manhole: 
- Pipes inside the manhole are horizontal

- Nominal Diameter 4 in.

- $30 \mathrm{ft}$ of steel pipe 5/32 in. thick

- Status Quo insulation thickness $=1.5$ in.

- Ceramic Paint insulation thickness $\geq 0.045$ in.

- The system operates 24 Hours/Day, 356 Days/Year.

- The temperature of the water inside the carrier pipe is $200^{\circ} \mathrm{F}$

- The boiler Efficiency Factor is 0.8

- The cost of fuel is $\$ 0.6 /$ Therm

\section{Estimating Method}

The temperatures were measured at a manhole containing a line insulated with 1.5 in. mineral insulation and a line insulated with a minimum of 45 mils of ceramic paint. The measures were performed 17 April 2006 at 6:00 A.M. The ambient temperature outside the manhole at that time was 66 ${ }^{\circ} \mathrm{F}$. The 30 years Normal Daily Mean Temperature for Columbia ${ }^{1}, \mathrm{SC}$ is $63.6^{\circ} \mathrm{F}$. As a consequence, the readings are representative of the normal daily mean temperature for the area and can be used to estimate the annual energy losses under both types of insulation.

For the pipe with ceramic paint insulation, temperature on top of the ceramic paint was $153^{\circ} \mathrm{F}$. For the pipe with $1.5 \mathrm{in}$. mineral wool insulation, the temperature on top of the insulation was $92{ }^{\circ} \mathrm{F}$. The temperature of water in the carrier pipe was known to be $200^{\circ} \mathrm{F}$.

For the status quo alternative, the values for Equation 3 are:

$$
\begin{aligned}
& r_{1}=2 \text { in.; } r_{2}=2.156 \text { in.; } r_{3}=3.656 \text { in.; } k_{s}=26.2 \mathrm{Btu} /\left(\mathrm{Hr}-\mathrm{Ft}-{ }^{\circ} \mathrm{F}\right) ; \\
& k_{a}=0.024 \mathrm{Btu} /\left(\mathrm{Hr}-\mathrm{Ft}^{\circ}{ }^{\circ} \mathrm{F}\right) ; \mathrm{T}_{\mathrm{m}}=200^{\circ} \mathrm{F} ; \mathrm{T}_{\mathrm{o}}=92^{\circ} \mathrm{F}
\end{aligned}
$$

$\mathrm{T}_{\mathrm{m}}=$ Inside temperature of the pipe

$\mathrm{T}_{\mathrm{o}}=$ Outside temperature of the insulation

For the above values, the energy loss in the carrier pipe inside the average manhole per foot of pipe is $31 \mathrm{Btu} / \mathrm{Hr}-\mathrm{Ft}$ and the annual cost of that energy for the average manhole is $\$ 60$.

1 http://Iwf.ncdc.noaa.gov/oa/climate/online/ccd/meantemp.html 
For the ceramic paint alternative, the values for equation 3 are:

$$
\begin{aligned}
& r_{1}=2 \text { in.; } r_{2}=2.156 \text { in.; } r_{3}=2.205 \text { in.; } k_{s}=26.2 \mathrm{Btu} /\left(\mathrm{Hr}-\mathrm{Ft}-{ }^{\circ} \mathrm{F}\right) ; \\
& k_{a}=0.005 \mathrm{Btu} /\left(\mathrm{Hr}-\mathrm{Ft}-{ }^{\circ} \mathrm{F}\right) ; \mathrm{T}_{\mathrm{m}}=200{ }^{\circ} \mathrm{F} ; \mathrm{T}_{\mathrm{o}}=153^{\circ} \mathrm{F}
\end{aligned}
$$

$\mathrm{T}_{\mathrm{m}}=$ Inside temperature of the pipe

$\mathrm{T}_{\mathrm{o}}=$ Outside temperature ceramic paint

For the above values, the energy loss in the carrier pipe inside the average manhole per foot of pipe is $640 \mathrm{Btu} / \mathrm{Hr}-\mathrm{Ft}$ and the annual cost of that energy for the average manhole is $\$ 1,244$. Table $\mathrm{C}_{3}$ below contains a summary of the calculations.

Table C3. Summary of Energy Calculations.

\begin{tabular}{llll} 
& \multicolumn{3}{c}{ Alternatives } \\
Variables & Units & Status Quo & Ceramic Paint \\
Tm & ${ }^{\circ} \mathrm{F}$ & 200 & 200 \\
To & ${ }^{\circ} \mathrm{F}$ & 92 & 153 \\
$\mathrm{r}_{1}$ & $\mathrm{In}$. & 2 & 2 \\
$\mathrm{r}_{2}$ & $\mathrm{In}$. & 2.156 & 2.156 \\
$\mathrm{r}_{3}$ & $\mathrm{In}$. & 3.656 & 2.206 \\
$\mathrm{k}_{\mathrm{s}}$ & $\mathrm{Btu} /\left(\mathrm{Hr}-\mathrm{Ft}-{ }^{\circ} \mathrm{F}\right)$ & 26.2 & 26.2 \\
$\mathrm{k}_{a}$ & $\mathrm{Btu} /\left(\mathrm{Hr}-\mathrm{Ft}-{ }^{\circ} \mathrm{F}\right)$ & 0.024 & 0.056 \\
Q/L & $\mathrm{Btu} / \mathrm{Hr}-\mathrm{Ft}$ & 31 & 716 \\
$\mathrm{~L}$ & $\mathrm{Ft}$ & 30 & 30 \\
Q & $\mathrm{Btu} / \mathrm{Hr}$ & 925 & 21,478 \\
QD & $\mathrm{Btu} / \mathrm{Day}$ & 22,189 & 515,483 \\
Boiler Efficiency & $\mathrm{EF}$ & 0.8 & 0.8 \\
Energy Unit Cost & \$/Term & 0.6 & 0.6 \\
Daily Cost & \$/Day & $\$ 0.17$ & $\$ 3.87$ \\
Annual Cost & \$/Year & $\$ 59.91$ & $\$ 1,391.80$
\end{tabular}

The \$60/Year Annual Cost of Energy Lost in the Status Quo was estimated assuming a dry insulation. If the insulation is wet, the losses can increase by a factor of $5^{1}$. Assuming that the insulation is wet $50 \%$ of the time, the annual cost is then: Annual Cost of Energy Lost in the Status Quo $=\$ 60 \mathrm{x}$ $5 \times 50 \%=\$ 150 /$ Year

\footnotetext{
1 Engineer Management System for Heat Distribution Systems: Project level; NMD and Associates; Alexandria, VA; February 1996
} 


\section{Annex 2: ECONPACK Output File}

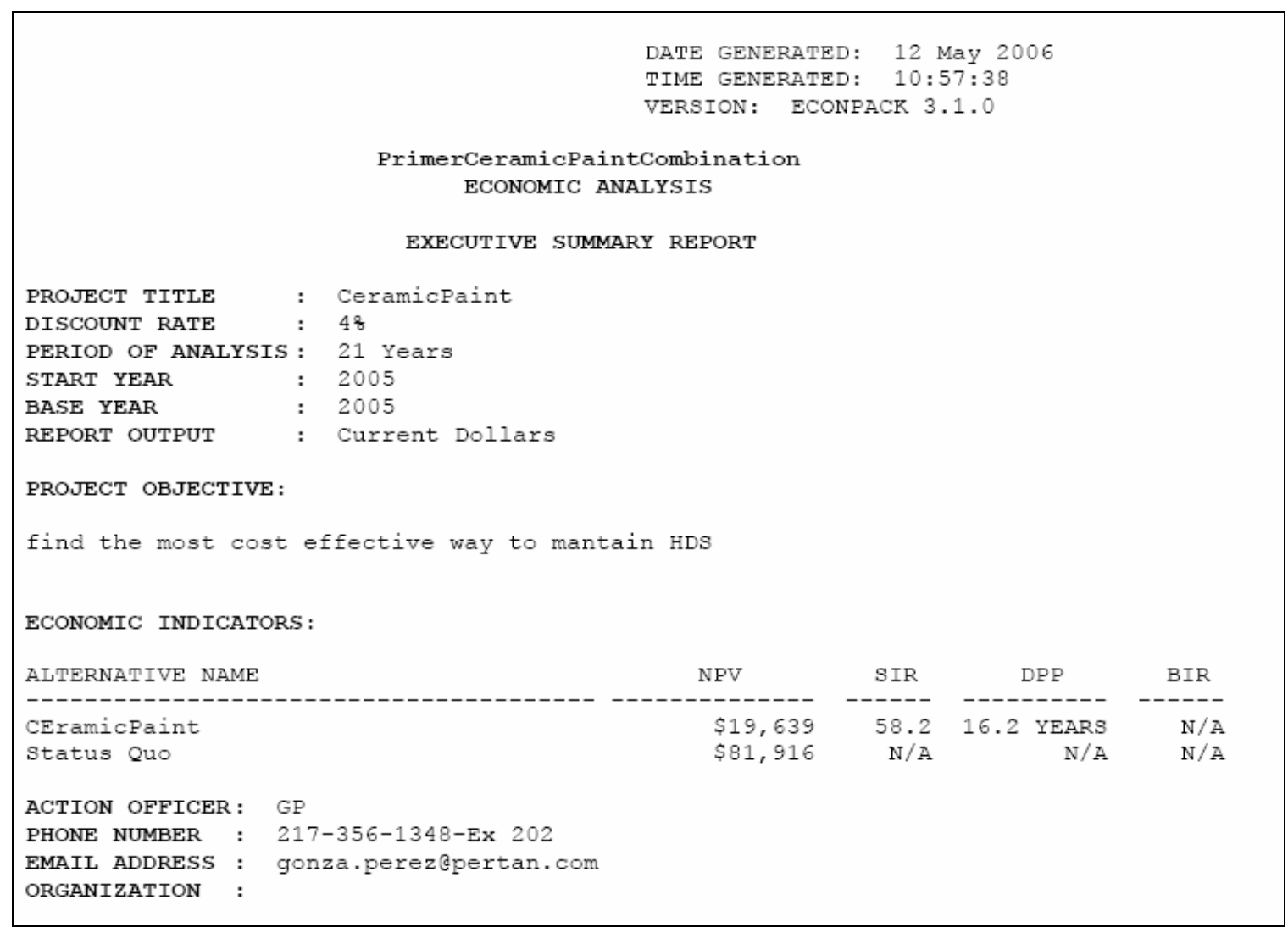

\section{ECONOMIC ANALYSIS GRAPH 1}

Cumulative Net Present Value

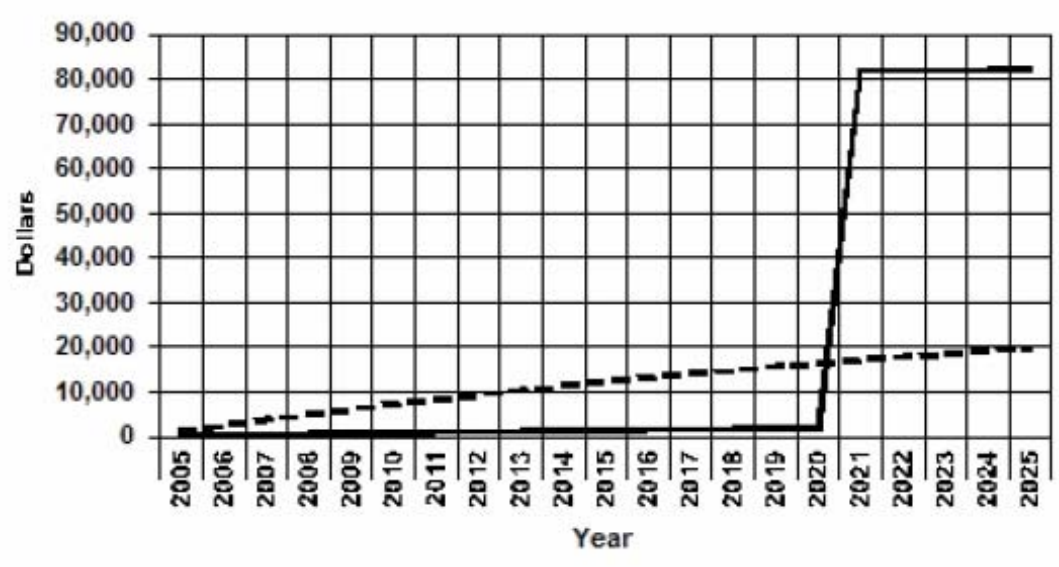




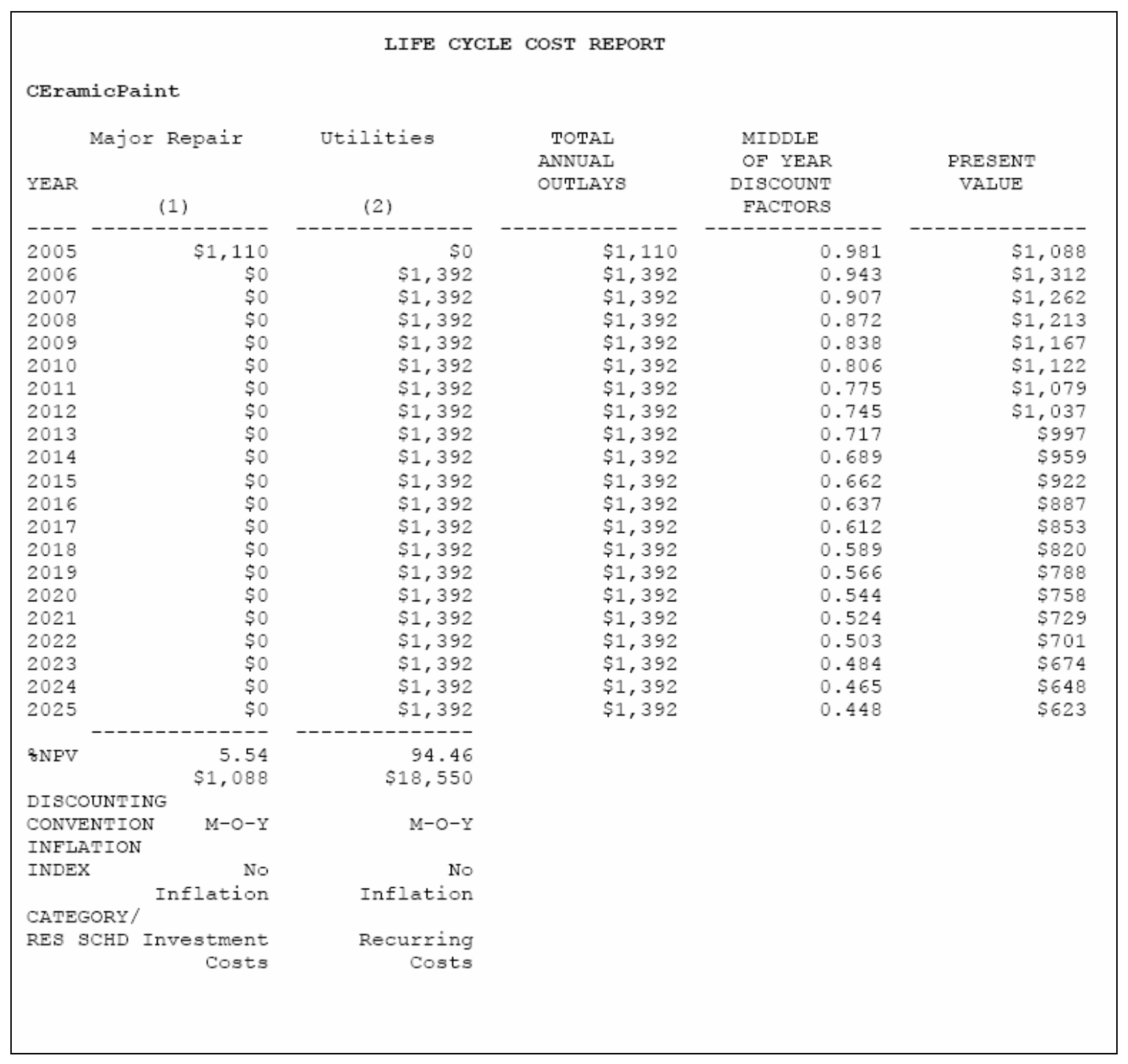




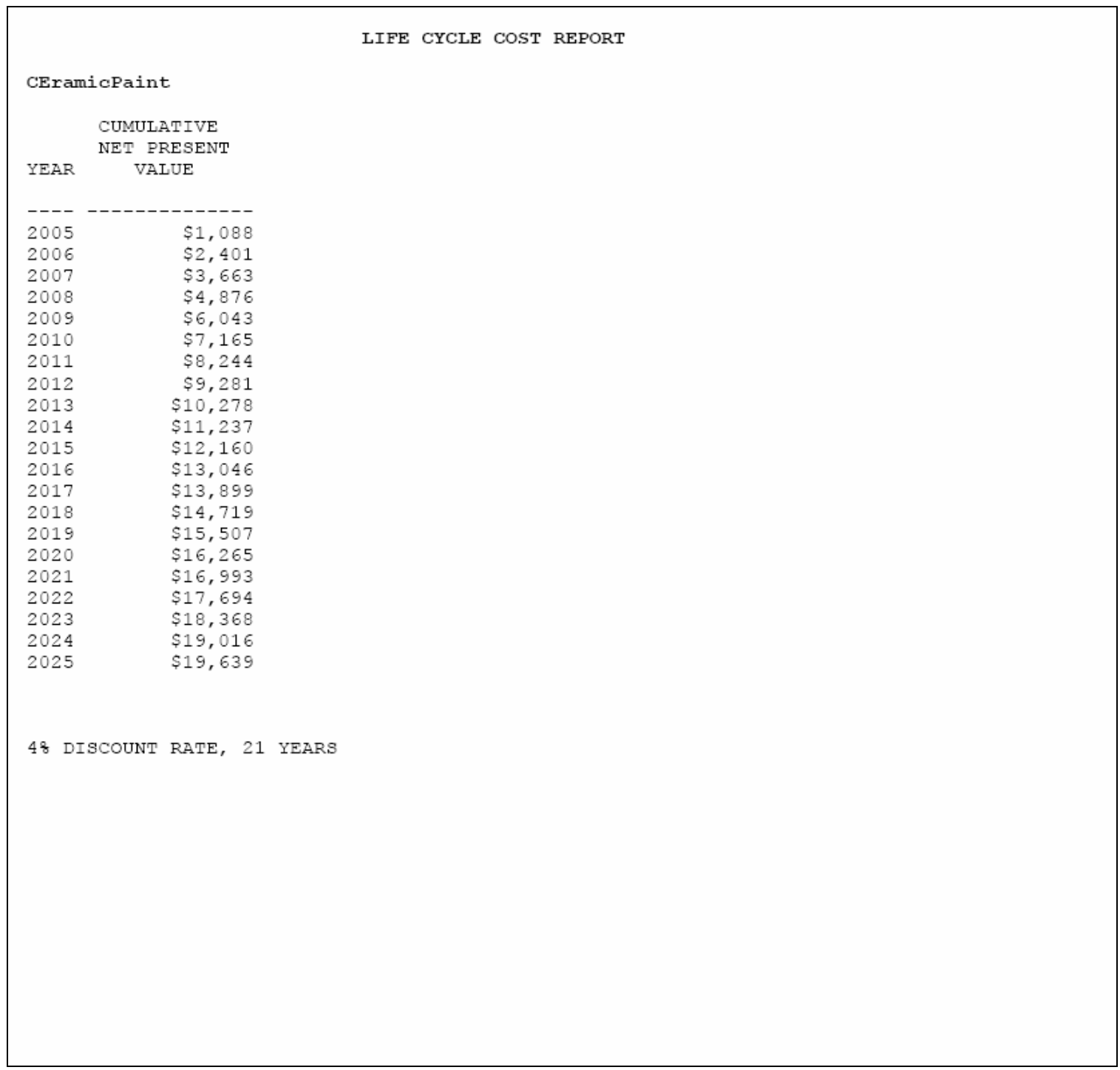




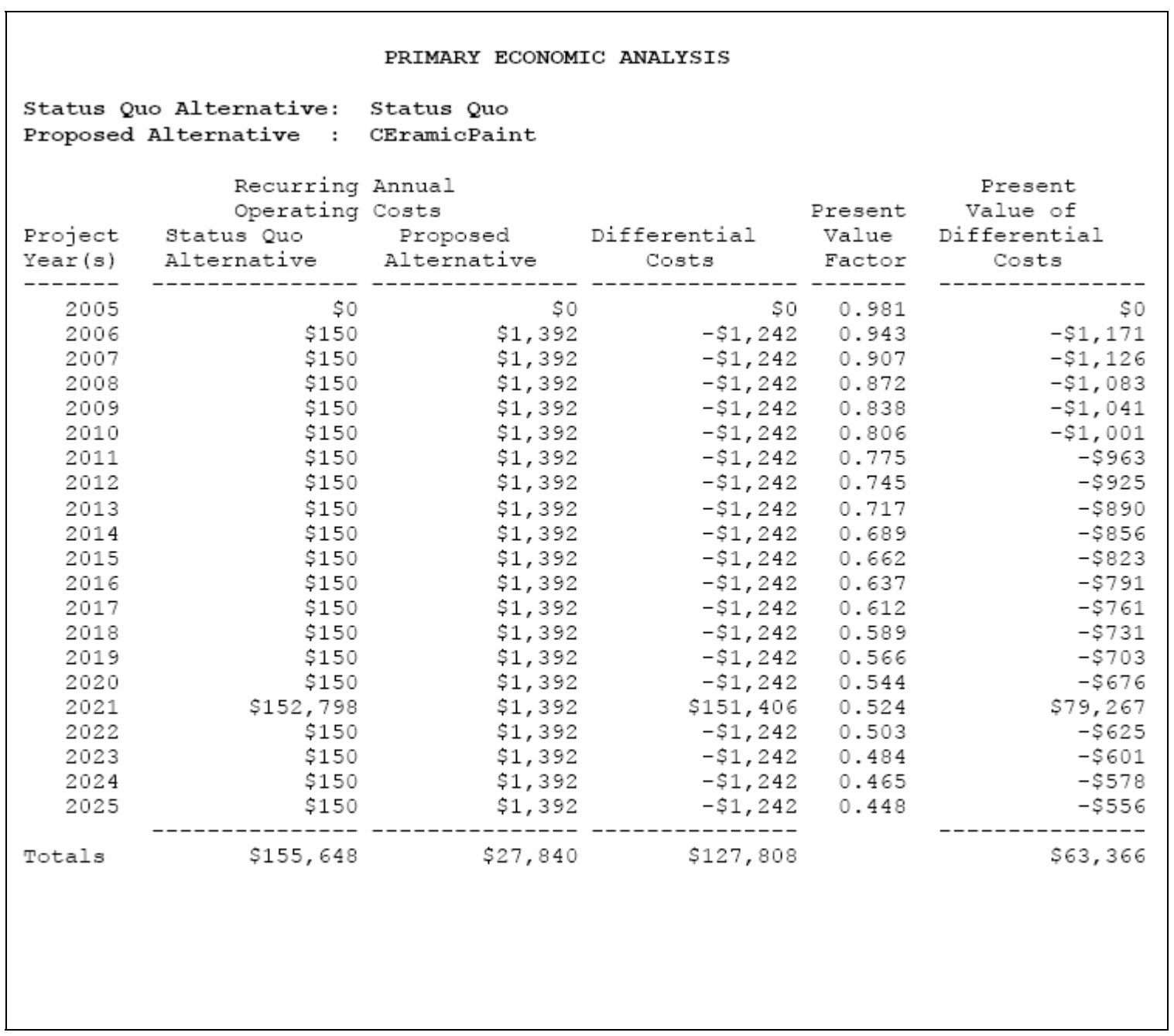




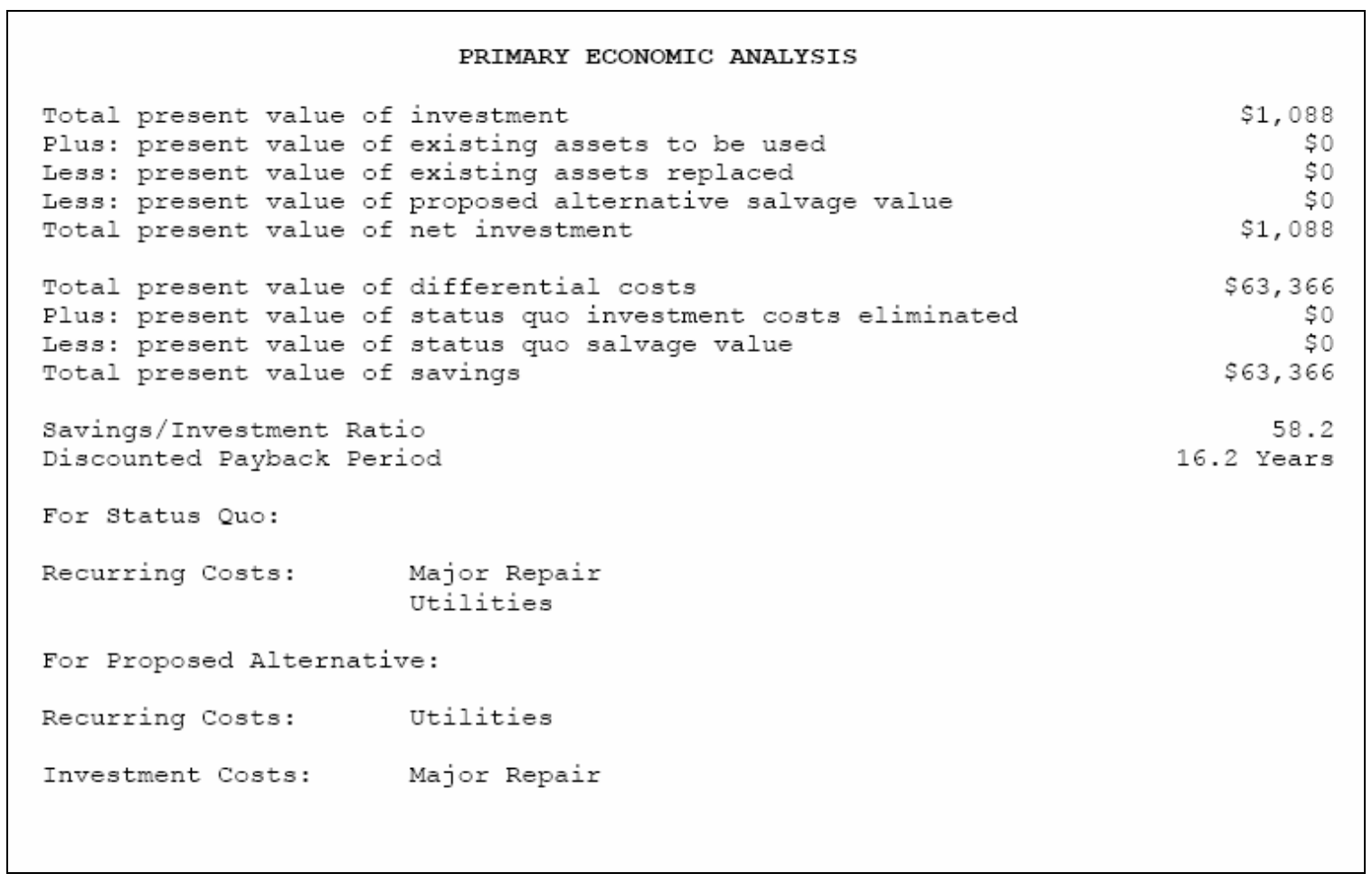




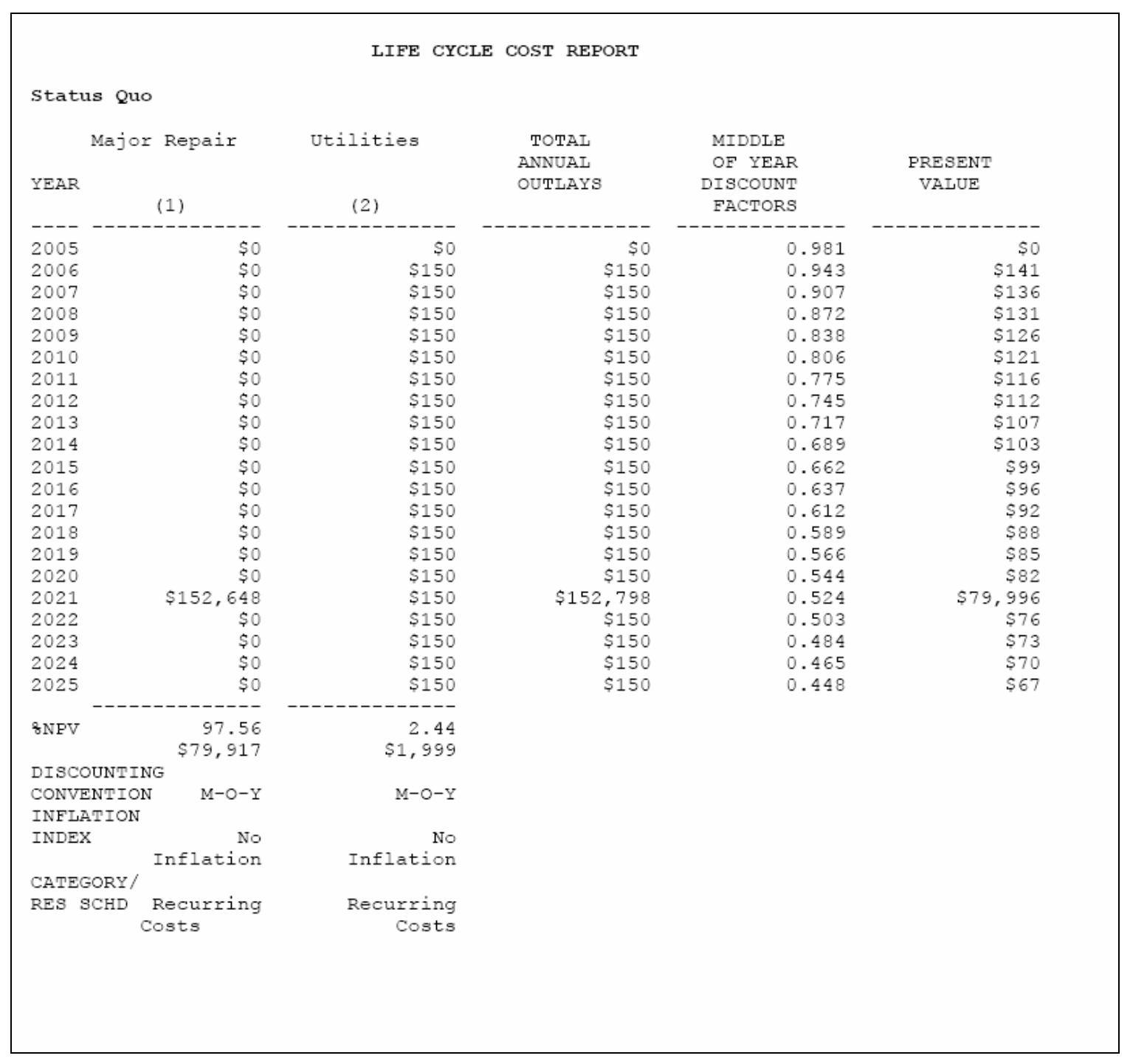




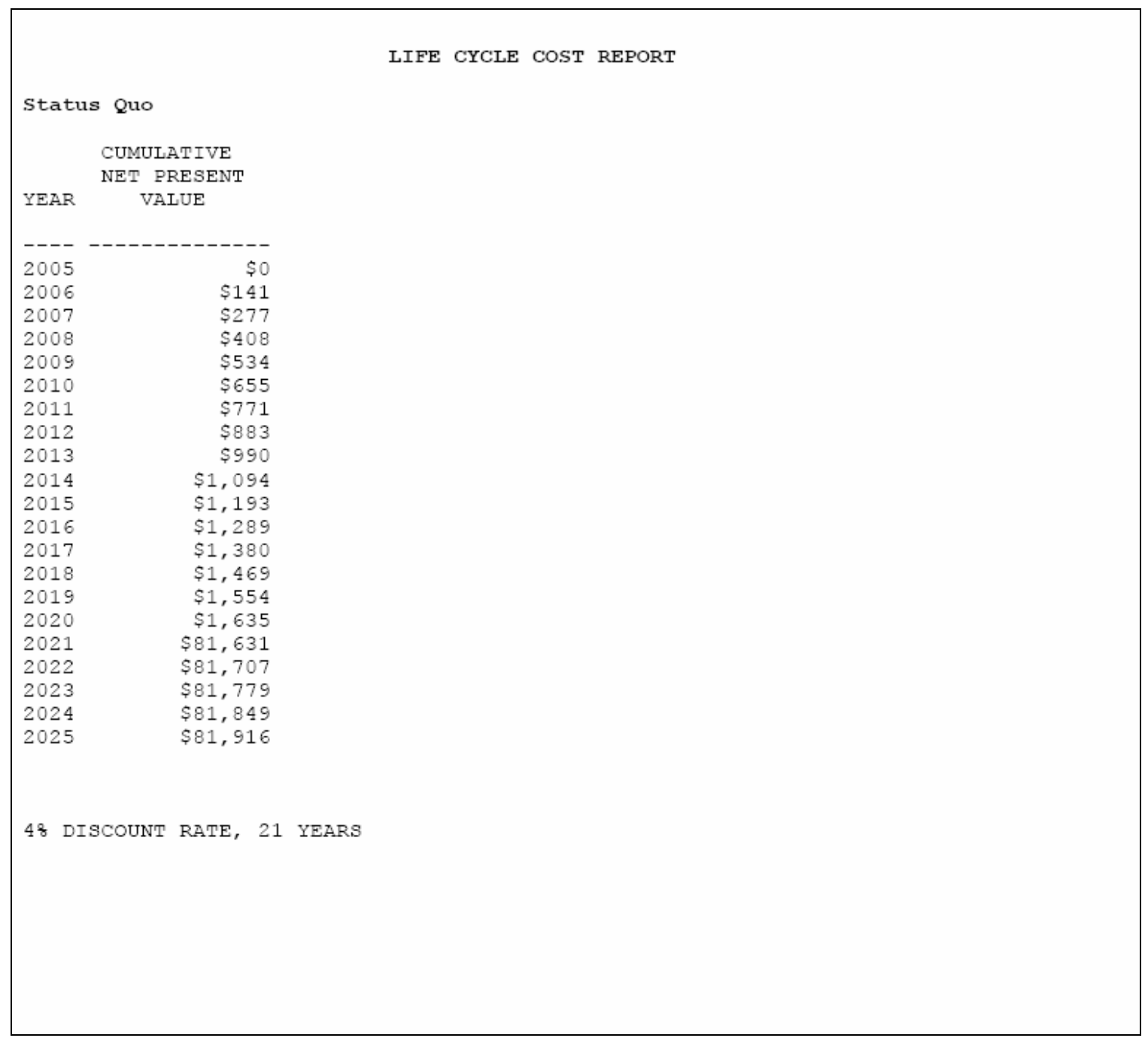


COST SENSITIVITY ANALYSIS 1

TITLE: MajorRepairstatusQuo

This sensitivity analysis checks for alternative status Quo to be ranked least cost

as a result of changes in the expense item(s) listed below:

ALTERNATIVE $\quad$ EXPENSE ITEM(S)

- - - - - - - - -

CEramicPaint $\quad$ * NoTHING CHANGED * *

Status Quo Major Repair

The selected expense items are allowed to vary from a value of -100.008 to .008

ALTERNATIVE

NET PRESENT VALUE

CEramicPaint

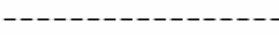

$\$ 19,639$

status Quo

$\$ 81,916$

RESULTS :

For alternative Status Quo to be ranked least cost, reduce the selected expense item(s) by more than 77.938 .

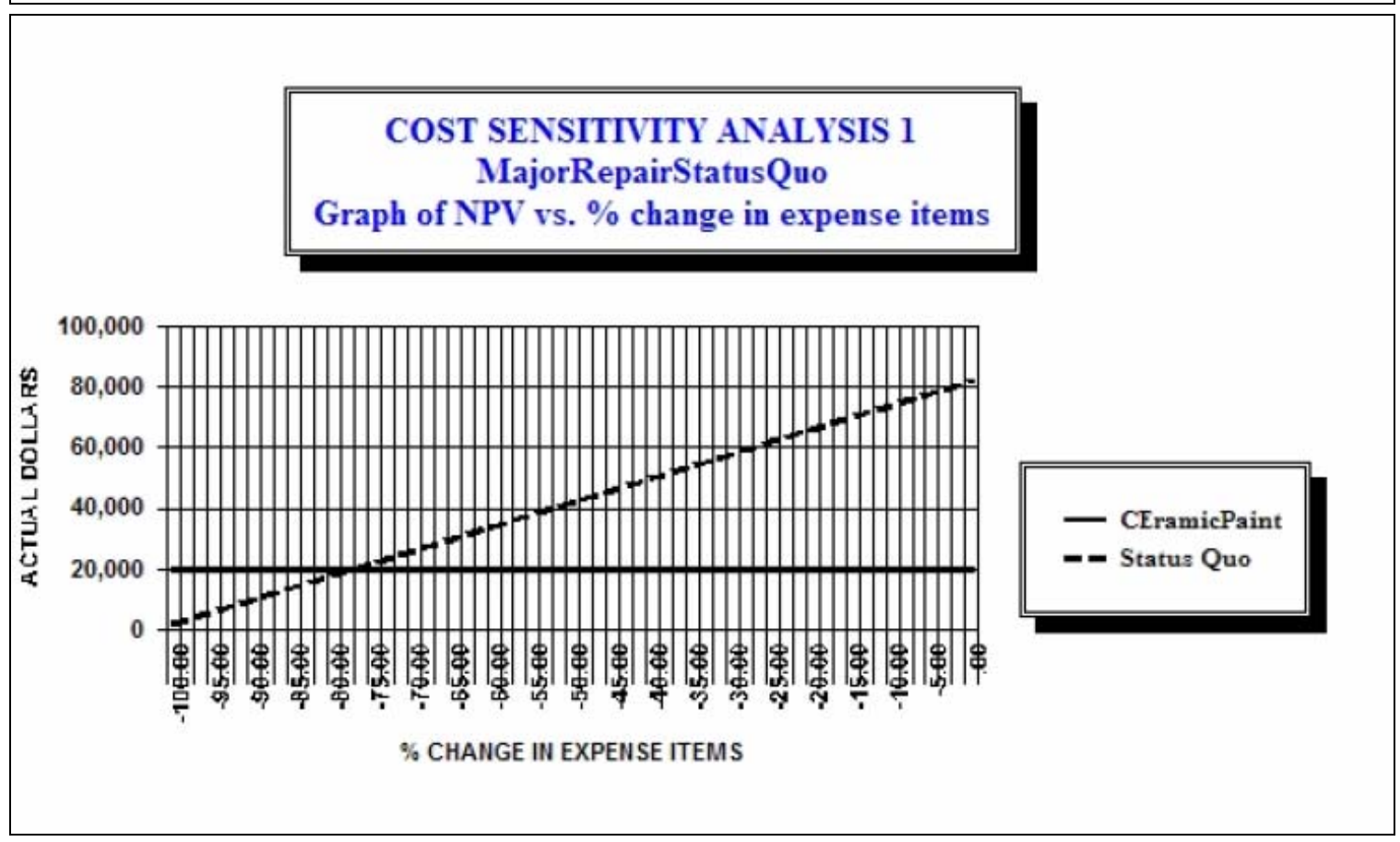


COST SENSITIVITY ANALYSIS 2

TITLE: Energy Losses for Ceramic Paint

This sensitivity analysis checks for alternative Status Quo to be ranked least cost as a result of changes in the expense item(s) listed below:

ALTERNATIVE

$---------1$

Status Quo

CEramicPaint

The selected expense items are allowed to vary from a value of -100.008 to 200.008

ALTERNATIVE

CreramicPaint

Status Quo

NET PRESENT VALUE

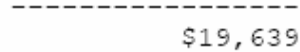

RESULTS :

The ranking of alternatives is insensitive to changes in the selected expense item(s), within the allowable range of variation.

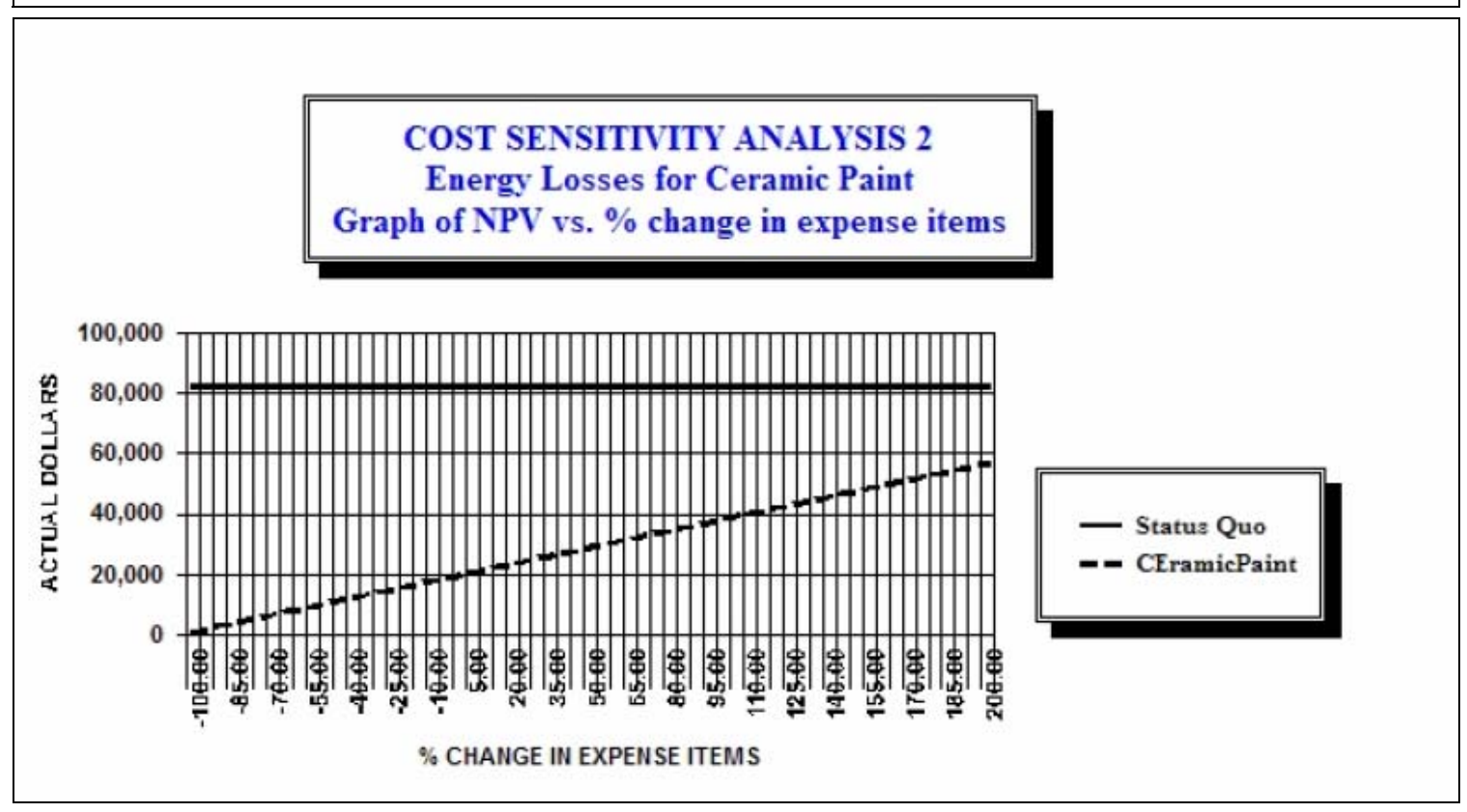




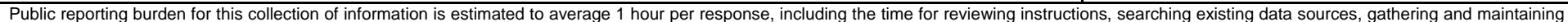

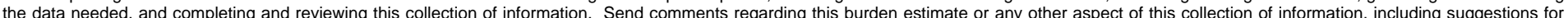

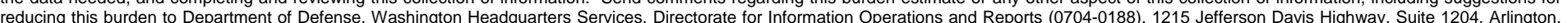

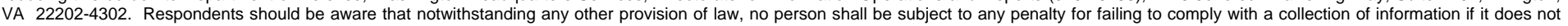
display a currently valid OMB control number. PLEASE DO NOT RETURN YOUR FORM TO THE ABOVE ADDRESS.
1. REPORT DATE (DD-MM-YYYY) 2. REPORT TYPE June 2007 Final

4. TITLE AND SUBTITLE

Innovative Corrosion-Resistant Coatings for Heat Distribution Piping at Fort Jackson

6. AUTHOR(S)
Charles P. Marsh, Alfred D. Beitelman, and Ryan J. Franks

3. DATES COVERED (From - To)

5a. CONTRACT NUMBER

5b. GRANT NUMBER

5c. PROGRAM ELEMENT NUMBER

Corrosion Prevention and Control

5d. PROJECT NUMBER

IMA-2

5e. TASK NUMBER

MIPR5CCERB1011, MIPR5CROBB1012

5f. WORK UNIT NUMBER

7. PERFORMING ORGANIZATION NAME(S) AND ADDRESS(ES)

8. PERFORMING ORGANIZATION REPORT NUMBER

U.S. Army Engineer Research and Development Center

ERDC/CERL TR-07-29

Construction Engineering Research Laboratory

P.O. Box 9005

Champaign, IL 61826-9005

9. SPONSORING I MONITORING AGENCY NAME(S) AND ADDRESS(ES)

10. SPONSOR/MONITOR'S ACRONYM(S)

U.S. Army Installation Management Command

Engineering Office, Directorate of Public Works (IMPW-E)

2511 Jefferson Davis Hwy.

Arlington, VA 22202

11. SPONSOR/MONITOR'S REPORT NUMBER(S)

\section{DISTRIBUTION / AVAILABILITY STATEMENT}

Approved for public release; distribution is unlimited.

\section{SUPPLEMENTARY NOTES}

\section{ABSTRACT}

Heat distribution systems are an integral part of military facility and installation infrastructure. These systems include numerous manholes that represent weak points in the overall efficiency, reliability, and service life of heating infrastructure. This report discusses the demonstration of an insulating ceramic paint and primer applied to coat manholes, piping, and appurtenances at Fort Jackson, SC, and the results obtained. The ceramic paint helps to prevent corrosion and heat loss while also significantly mitigating hazardous working conditions. Because these issues are important operational concerns for every military facility, ceramic coatings represent an element of building engineering that should be considered for wider adoption in heat distribution systems.

\section{SUBJECT TERMS}

coatings, corrosion control, heat distribution systems, manholes, paints, Fort Jackson, SC

\begin{tabular}{|c|c|c|}
\hline \multicolumn{3}{|c|}{ 16. SECURITY CLASSIFICATION OF: } \\
\hline a. REPORT & b. ABSTRACT & c. THIS PAGE \\
\hline Unclassified & Unclassified & Unclassified \\
\hline
\end{tabular}

17. LIMITATION OF ABSTRACT
18. NUMBER OF PAGES

71 19a. NAME OF RESPONSIBLE PERSON

19b. TELEPHONE NUMBER (include area code) 